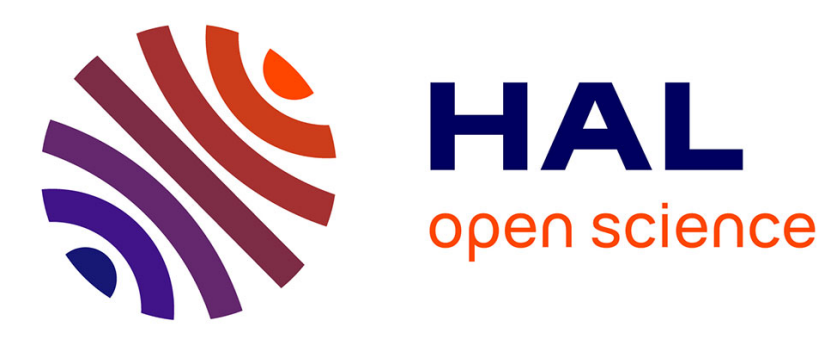

\title{
Dye-Sensitized Photoelectrosynthesis Cell (DSPEC) for Benzyl Alcohol Oxidation using Zinc Porphyrin Sensitizer and TEMPO Catalyst
}

Emmanouil Nikoloudakis, Palas Baran Pati, Georgios Charalambidis, Darya S Budkina, Stéphane Diring, Aurélien Planchat, Denis Jacquemin, Eric Vauthey, Athanassios G Coutsolelos, Fabrice Odobel

\section{To cite this version:}

Emmanouil Nikoloudakis, Palas Baran Pati, Georgios Charalambidis, Darya S Budkina, Stéphane Diring, et al.. Dye-Sensitized Photoelectrosynthesis Cell (DSPEC) for Benzyl Alcohol Oxidation using Zinc Porphyrin Sensitizer and TEMPO Catalyst. ACS Catalysis, 2021, 11 (19), pp.12075-12086. 10.1021/acscatal.1c02609 . hal-03419877

\section{HAL Id: hal-03419877 \\ https://cnrs.hal.science/hal-03419877}

Submitted on 8 Nov 2021

HAL is a multi-disciplinary open access archive for the deposit and dissemination of scientific research documents, whether they are published or not. The documents may come from teaching and research institutions in France or abroad, or from public or private research centers.
L'archive ouverte pluridisciplinaire HAL, est destinée au dépôt et à la diffusion de documents scientifiques de niveau recherche, publiés ou non, émanant des établissements d'enseignement et de recherche français ou étrangers, des laboratoires publics ou privés. 


\title{
Dye-Sensitized Photoelectrosynthesis Cell (DSPEC)
}

\section{for Benzyl Alcohol Oxidation using Zinc Porphyrin}

\section{Sensitizer and TEMPO Catalyst}

Emmanouil Nikoloudakis, ${ }^{[\mathrm{a}]}$ Palas Baran Pati, ${ }^{[\mathrm{b}]}$ Georgios Charalambidis, ${ }^{[\mathrm{a}]}$

Darya S. Budkina, ${ }^{[\mathrm{c}]}$ Stéphane Diring,${ }^{[\mathrm{b}]}$ Aurélien Planchat,${ }^{[\mathrm{b}]}$ Denis

Jacquemin, ${ }^{*[\mathrm{~b}]}$ Eric Vauthey, ${ }^{*[\mathrm{c}]}$ Athanassios G. Coutsolelos, ${ }^{*[\mathrm{a}]}$ and Fabrice Odobel, $*^{[\mathrm{b}]}$

${ }^{[a]}$ Laboratory of Bioinorganic Chemistry, Department of Chemistry, University of Crete, Voutes Campus, 70013 Heraklion,Crete, Greece.E-mail: acoutsol@uoc.gr

${ }^{[b]}$ Université de Nantes, CNRS, UMR 6230, Chimie et Interdisciplinarité: Synthèse, Analyse, Modélisation (CEISAM), 2 rue de la Houssinière, 44322 Nantes cedex 3, France. E-mails: Denis.Jacquemin@univ-nantes.frand Fabrice.Odobel@univ-nantes.fr

${ }^{[c]}$ Department of Physical Chemistry, University of Geneva, 30 Quai Ernest-Ansermet, CH1211 Geneva, Switzerland.E-mail: Eric.Vauthey@unige.ch

\section{Keywords}

artificial photosynthesis; photo-oxidation; photoelectrochemical cells (PEC); dye sensitized solar cell; solar energy conversion; photocatalysis; alcohol dehydrogenation.

\begin{abstract}
Exploring a catalytic reaction, other than water oxidation, at the photoanode of a photoelectrochemical cell is probably a key feature to more efficiently generate the electrons needed to produce solar fuels. In this framework, we describe herein the fabrication of a $\mathrm{TiO}_{2}$
\end{abstract}


based DSPEC using a zinc porphyrin ( $\mathrm{ZnP})$ sensitizer and a TEMPO organo-catalyst that quite efficiently catalyzes light driven oxidation of methoxybenzyl alcohol into aldehyde. Two dyads ZnP-TEMPO, differing by the anchoring group (carboxylic acid and hydroxamic acid) on $\mathrm{ZnP}$, were prepared and their electrochemical, absorption, emission properties were recorded and quantum chemical modelling was realized. The photovoltaic performances in DSSCs were first examined in order to optimize the dyeing conditions and compare the relative efficiencies of the compounds. The dyads substituted with TEMPO outperform the reference zinc porphyrin lacking TEMPO with a much higher Jsc and Voc. The photocatalytic properties after immobilization on $\mathrm{TiO}_{2}$ nanocrystalline films towards para-methoxy benzyl alcohol oxidation were explored in borate buffer and in acetonitrile electrolyte. In borate buffer, the optimal $\mathrm{pH}$ was 8 and using the dyad ZnP-TEMPO anchored with hydroxamic acid, para-methoxy benzaldehyde was selectively produced with average photocurrent density of $200 \mu \mathrm{A} / \mathrm{cm}^{2}$, a faradaic efficiency of $82 \%$, a TON of 26 , and a TOF of $47 \mathrm{~h}^{-1}$. In acetonitrile in presence of $0.1 \mathrm{M}$ of $\mathrm{N}$-methyl-imidazole, the same dyad gives an average photocurrent density of about $100 \mu \mathrm{A} / \mathrm{cm}^{2}$, a faradaic efficiency of $76 \%$, a TON of 13 , and a TOF of $24 \mathrm{~h}^{-1}$. The stability of the anchor is crucial in acetonitrile electrolyte, where the dyad is quite soluble, since only the dyad functionalized with hydroxamic acid is compatible with these organic solvent conditions. Overall this study paves the way to the development of more efficient and probably more stable $\mathrm{TiO}_{2}$ based DSPECs for alcohol oxidation that could advantageously complement those devoted to water oxidation.

\section{Introduction}

Degradation of the biosphere by the pollution generated from fossil fuels burning has stimulated an intense research activity devoted to the storage of sunlight as chemical fuels towards a sustainable society. ${ }^{1,2,3}$ To this end, the development of photoelectrochemical cell (PEC) is one of the most investigated and probably the most promising approach. ${ }^{4-6}$ In such systems, a compound is reduced at the photocathode by the electrons produced by the oxidation of a substrate at the photoanode. In many cases, water is the source of electrons upon its oxidation into oxygen. Although this reaction is interesting because water is a very abundant and harmless compound, it is a challenging transformation since it involves four oxidizing equivalents. Moreover, it is energetically costing as it requires a potential of $1.23 \mathrm{~V}$ vs. NHE at $\mathrm{pH}=0$ and it is usually catalyzed by expensive noble metal based catalysts. ${ }^{7,8}$ All these factors taken together explain why water oxidation is most often the limiting process that decreases the overall efficiency of PECs. Water oxidation releases oxygen, which is a product of poor economic value, but they are several attractive alternative reactions that can produce more added values products. ${ }^{9-11}$ For example, replacement of water oxidation by the selective oxidation of organic molecules, such as alcohols, is certainly a valuable strategy to produce high-valued carbonyl compounds, and at the same time it is possible to reduce various substrates such as protons, carbon dioxide or nitrogen at the other electrode in a tandem system. ${ }^{12-14}$ Besides generating more economically valuable materials at both electrodes, the advantages of alcohol oxidation stems from the fact that this reaction necessitates a lower potential than water oxidation $(-0.143 \mathrm{~V} v$ s. NHE for benzyl alcohol 
oxidation versus $1.23 \mathrm{~V} v$ s. NHE for water oxidation at $\mathrm{pH}=0$ for both $)^{15}$ and only two holes instead of four, and consequently only two photons. In addition, light driven alcohol oxidation could represent an attractive, cheaper, safer and more environmentally benign oxidation protocol than the usual noxious chemical approaches that employ stoichiometric amounts of toxic oxidants. ${ }^{16}$ Moreover, biomass remains a largely unexploited supply of raw materials for the chemical industry and is indeed an immense source of alcohols. ${ }^{17}$ There are several approaches to design a PEC and among them dye-sensitized photoelectrosynthesis cell (DSPEC) is particularly interesting, because it does not involve low bandgap semiconductors, which present the disadvantage of being usually unstable in contact with an aqueous electrolyte upon light irradiation. ${ }^{18}$ On the other hand, the performances of DSPECs are usually modest, most certainly because the dye must feed the catalyst with several redox equivalents before catalysis occurs. ${ }^{19-22}$ This requirement is particularly demanding in the context of a photosensitized electrode, because it implies that: i) the dye photoexcitation frequency is high, so that the same dye absorbs photons at close intervals in order to funnel several charges to the catalyst before charge recombination takes place, which is a difficult task with the low photon flux of sunlight, or ii) the lateral charge diffusion inside the monolayer of the chemisorbed molecules is quite efficient, at least faster than charge recombination, so as several different oxidized dyes could feed the catalyst with oxidation equivalents. $^{23-27}$ As a result, choosing an oxidation reaction which involves only two oxidizing equivalents, instead of four, could be a nice opportunity to alleviate the challenging multiple charge accumulation step in DSPEC. On this field, the seminal work of Meyer and co-workers ${ }^{28}$ was followed by a few other studies, ${ }^{19,29,30}$ but alcohol oxidation in DSPEC still remains an unexplored scientific topic today, particularly if one compares it with water oxidation. $^{31,32}$ All the previously reported studies of alcohol oxidation with DSPEC that we are aware of rely on a ruthenium polypyridine complex as catalyst ${ }^{19,28,31,32}$ and very often with a ruthenium tris-bipyridine based $\mathrm{TiO}_{2}$ sensitizer, although a few publications describe systems with an organic sensitizer. ${ }^{29,} 30,33,34$ Very recently, an interesting study reports a DSPEC type photoanode made of $\mathrm{TiO}_{2}$ film sensitized by a ruthenium tris-bipyridine complex that depolymerizes lignin with N-hydroxyphthalimide catalyst solubilized into an acetonitrile based electrolyte. ${ }^{35}$ A catalytic photocurrent density of about $130 \mu \mathrm{A} / \mathrm{cm}^{2}$ was measured upon light irradiation $\left(200 \mathrm{~mW} / \mathrm{cm}^{2}\right)$ with an applied potential of $0.75 \mathrm{~V}$ vs. SCE. Nitroxides in general and 2,2,6,6-tetramethyl-1-piperidine N-oxyl (TEMPO) in particular are very active, cheap and green catalysts for alcohol oxidation, ${ }^{36}$ that is even applied to chemical industry. ${ }^{37}$, ${ }^{38}$ Light driven alcohol oxidation catalyzed by a TEMPO derivative has been demonstrated in homogeneous systems with a dye in presence of a sacrificial electron acceptor (typically $\left.\mathrm{Co}\left(\mathrm{NH}_{3}\right)_{5} \mathrm{Cl}_{3}\right){ }^{39-43}$ TEMPO mediated alcohol oxidation was also described with a visible light absorbing n-type semiconductor such as $\mathrm{BiVO}_{4}$ or $\mathrm{WO}_{3}$ as photoanode. ${ }^{14,}{ }^{44-46}$ Interestingly, TEMPO derivatives were successfully implemented as redox mediators in dye sensitized solar cells proving that hole transfer could be efficiently realized from an oxidized sensitizer to the nitroxide radical even with a weak driving force. ${ }^{47-50}$ Moreover, visible light photocatalytic TEMPO-mediated oxidation of alcohols to aldehydes has been reported with dyes upon oxidative quenching by a sacrificial electron acceptor in solution or with a hybrid system consisting of $\mathrm{TiO}_{2}$ or $\mathrm{ZnO}$ dye-sensitized nanoparticles. ${ }^{39,40,42,43}$ 
In this study, we investigate the fabrication of a $\mathrm{TiO}_{2}$ based DSPEC for alcohol oxidation using for the first time a TEMPO catalyst covalently appended to an organic sensitizer (Figure 1). The purposes of this study are two folds. First, to explore the benefit of choosing a two holes oxidation reaction by comparing its efficiency with other reported DSPECs oxidizing water instead of alcohol. Second, to investigate the possibility of designing DSPEC with only abundant elements by replacing the classical ruthenium alcohol oxidation catalyst ${ }^{51}$ by a TEMPO derivative and to assess its potential in term of photocatalytic performance. Towards this objective, two dyads composed of a zinc porphyrin linked to a TEMPO were prepared and their photocatalytic properties in DSPECs investigated. Zinc porphyrin sensitizers were successfully used in DSPEC for water oxidation, ${ }^{52-56}$ legitimating such choice since the catalytic potential of TEMPO is less anodic than that of many water oxidation catalysts. Hydroxamic acid was selected as anchoring group in order to maintain a robust linkage to the $\mathrm{TiO}_{2}$ surface and avoid leaching of the dyad during photocatalysis. ${ }^{57-61}$ Indeed, oxidation catalysis occurs more favorably in neutral and even basic conditions, ${ }^{62,63}$ in such conditions it is crucial to install a strong anchoring group to avoid premature desorption of the molecular system.

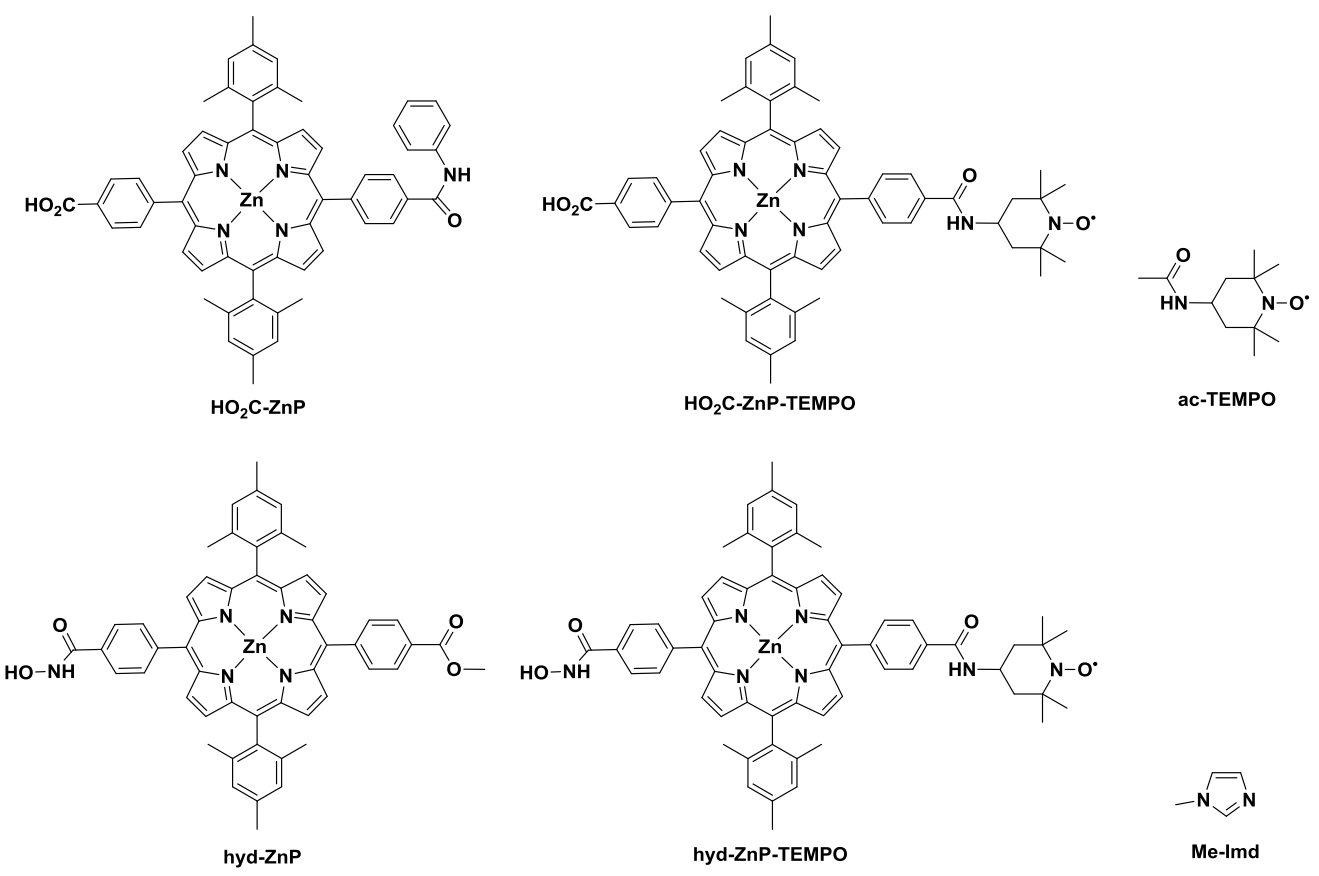

Figure 1. Structures of the compounds used in this study.

Overall, this study highlights that alcohol oxidation in DSPEC with TEMPO organo-catalyst activated by an organic dye is a promising and valuable strategy to replace classical water oxidation, since quite good efficiency could be demonstrated with ZnP-TEMPO dyads. The system works both in aqueous and organic solvents and the covalent attachment of the catalyst to the dye is not absolutely mandatory to achieve good photocatalytic performances, but it presents the real advantage of providing an easier recovery of the catalyst and becomes unavoidable when the catalyst is insoluble in the electrolyte. 


\section{Results and discussion}

\section{Synthesis}

The synthetic approach for the preparation of the porphyrin dyads ZnP-TEMPO is illustrated in Scheme S1. Initially the $\mathbf{H O}_{2} \mathbf{C}-\mathbf{Z n P}-\mathrm{CO}_{2} \mathbf{H}$ porphyrin was synthesized according to the literature ${ }^{64}$ and then an amide coupling with $\mathrm{NH}_{2}$-TEMPO was conducted using HATU as coupling reagent, yielding the $\mathbf{H O}_{2} \mathbf{C}-Z \mathbf{Z P}$-TEMPO dyad. Subsequently, the carboxylic acid anchoring group was converted into hydroxamic acid by using hydroxylamine hydrochloride, affording the hyd-ZnP-TEMPO dyad. The synthetic procedure of the reference derivative $\mathbf{H O}_{2} \mathbf{C}-\mathrm{ZnP}$ has been previously reported from our group, ${ }^{34}$ while the reference compound hyd-ZnP was prepared following similar reactions (Scheme S2). The successful synthesis of all the final and intermediate compounds was verified via ${ }^{1} \mathrm{H}$ and ${ }^{13} \mathrm{C}$ NMR spectroscopies (Figures S26-S34, ESI ${ }^{\dagger}$ ), and MALDI-TOF mass spectrometry. The assignment of the corresponding peaks was achieved through 2-D COSY, HMBC and HSQC NMR spectra analysis.

\section{Absorption and emission spectra}

The absorption spectra of the compounds were recorded in solution (Figures S1-S4) and on thin $\mathrm{TiO}_{2}$ films (Figure S5). The spectroscopic data are collected in Table 1. The spectra display the classical absorption bands of tetraaryl zinc porphyrin with a Soret transition located at $426 \mathrm{~nm}$ and two Q transitions peaking at 555 and $598 \mathrm{~nm}$. As expected, the appended TEMPO moiety does not alter the absorption spectra of the ZnP-TEMPO dyads, since there is no electronic communication between $\mathrm{ZnP}$ and TEMPO owing to the absence of a $\pi$-conjugated pathway (see also calculations below). Interestingly, both the reference zinc porphyrins and ZnP-TEMPO dyads are emissive with no significant extinction of the fluorescence in the dyads, indicating that TEMPO does not quench the porphyrin singlet excited state by electron transfer nor promotes intersystem crossing (Figures S6-S7).

Table 1. Absorption and emission properties of the compounds recorded in dichloromethane. Oxidation potentials of the compounds recorded on meso-ITO and Gibbs free energy of the electron injection $\left(\Delta \mathrm{G}_{\mathrm{inj}}\right)$ in $\mathrm{TiO}_{2}$ and hole shift reaction $\left(\Delta \mathrm{G}_{\mathrm{hs}}\right)$.

\begin{tabular}{|c|c|c|c|c|c|c|c|}
\hline Dye & $\begin{array}{c}\lambda_{\text {abs }} / \mathrm{nm}^{1}\left(\varepsilon / \mathrm{M}^{-}\right. \\
\left.{ }^{1} \mathrm{xcm}^{-1}\right)\end{array}$ & $\begin{array}{c}\lambda_{\mathrm{em}} \\
(\mathrm{nm})\end{array}$ & $\begin{array}{c}\mathrm{E}_{00}{ }^{\mathrm{a}} \\
(\mathrm{eV})\end{array}$ & $\begin{array}{c}\mathrm{E}_{\mathrm{Ox}}(\mathrm{TEMPO}) \\
(\mathrm{V} v s . \mathrm{SCE})\end{array}$ & $\begin{array}{c}\mathrm{E}_{\mathrm{Ox}}(\mathrm{ZnP}) \\
(\mathrm{V} v s . \\
\mathrm{SCE})\end{array}$ & $\begin{array}{c}\Delta \mathrm{G}_{\mathrm{inj}}{ }^{\mathrm{b}} \\
(\mathrm{eV})\end{array}$ & $\begin{array}{c}\Delta \mathrm{G}_{\mathrm{hs}}{ }^{\mathrm{c}} \\
(\mathrm{eV})\end{array}$ \\
\hline
\end{tabular}




\begin{tabular}{|c|c|c|c|c|c|c|c|}
\hline $\mathrm{HO}_{2} \mathrm{C}-\mathrm{ZnP}$ & $\begin{array}{l}426(452.3), 555 \\
(16.6), 598(5.7)\end{array}$ & 607,656 & 2.06 & - & 0.78 & $\begin{array}{c}-0.58 \\
(-0.41)\end{array}$ & - \\
\hline $\begin{array}{c}\mathrm{HO}_{2} \mathrm{C}-\mathrm{ZnP}- \\
\text { TEMPO }\end{array}$ & $\begin{array}{l}426(432.8), 557 \\
(16.8), 598(4.8)\end{array}$ & 607,655 & 2.06 & 0.73 & 0.79 & $\begin{array}{c}-0.57 \\
(-0.40)\end{array}$ & -0.06 \\
\hline hyd-ZnP & $\begin{array}{l}426(445.3), 556 \\
(16.6), 598(4.9)\end{array}$ & 607,656 & 2.06 & - & 0.86 & $\begin{array}{c}-0.50 \\
(-0.34)\end{array}$ & - \\
\hline $\begin{array}{l}\text { hyd-ZnP- } \\
\text { TEMPO }\end{array}$ & $\begin{array}{l}426(417.8), 557 \\
(15.5), 597(4.7)\end{array}$ & 606,655 & 2.06 & 0.74 & 0.84 & $\begin{array}{c}-0.52 \\
(-0.35)\end{array}$ & -0.1 \\
\hline
\end{tabular}

${ }^{\text {a }}$ determined with the wavelength $\left(\lambda_{\text {inter }}\right)$ at the intersection of the normalized absorption and emission spectra with the equation $\mathrm{E}_{00}=1240 / \lambda_{\text {inter. }}{ }^{\mathrm{b}}$ calculated according to the equation: $\Delta \mathrm{G}_{\text {inj }}=\mathrm{E}_{\mathrm{Ox}}(\mathrm{ZnP})-\mathrm{E}_{00}-\mathrm{E}_{\mathrm{CB}}\left(\mathrm{TiO}_{2}\right)$, with $\mathrm{E}_{\mathrm{CB}}\left(\mathrm{TiO}_{2}\right)=-0.7 \mathrm{~V}$ vs. SCE in acetonitrile ${ }^{65}$ and in parentheses in buffer at $\mathrm{pH}=8$ with $\mathrm{E}_{\mathrm{CB}}\left(\mathrm{TiO}_{2}\right)=-0.87 \mathrm{~V} v$ s. SCE at $\mathrm{pH}=$ $8 .^{66 \mathrm{c}}$ calculated according to the equation: $\Delta \mathrm{G}_{\mathrm{hs}}=\mathrm{E}_{\mathrm{Ox}}(\mathrm{TEMPO})-\mathrm{E}_{\mathrm{Ox}}(\mathrm{ZnP})$.

\section{Electrochemistry}

The redox potentials of the zinc porphyrin and TEMPO were investigated by cyclic voltammetry after chemisorption on mesoporous indium tin oxide (meso-ITO) in acetonitrile containing lithium perchlorate $(0.1 \mathrm{M})$ as supporting electrolyte (Figures S8-S9). The two oxidation processes are quite close and consequently are not well separated in the cyclic voltammograms. However, it is clear that zinc porphyrin oxidation occurs at about $100 \mathrm{mV}$ higher potential than that of TEMPO, leaving a modest, but non null, driving force for the hole shift reaction from oxidized zinc porphyrin to TEMPO $\left({ }^{+} \mathrm{ZnP}-\mathrm{TEMPO} \rightarrow \mathrm{ZnP}-\right.$ $\mathrm{TEMPO}^{+}$). Efficient electron transfer from TEMPO to an oxidized sensitizer on $\mathrm{TiO}_{2}$ with a small Gibbs free energy $(-0.18 \mathrm{eV})$ was reported, illustrating that such process can occur with weak driving force. ${ }^{47}$ On the other hand, the electron injection reaction is thermodynamically favorable by at least $-0.37 \mathrm{eV}$ in borate buffer at $\mathrm{pH}=8$ (Table 1). Upon addition of paramethoxybenzyl alcohol (MeO-Ph- $\left.\mathrm{CH}_{2} \mathrm{OH}\right)$ in acetonitrile electrolyte, the cyclic voltammogram of the dyad ZnP-TEMPO on meso-ITO shows the appearance of an intense irreversible wave attributed to the catalytic oxidation of alcohol by TEMPO, with an onset potential at $0.74 \mathrm{~V}$ vs. SCE (Figure S10).

\section{Quantum chemical calculations}

We have performed DFT calculations on hyd-ZnP-TEMPO (see the ESI ${ }^{\dagger}$ for technical details). First, the calculations confirmed that the unpaired electron is confined on the TEMPO and that vertical oxidation yield a change of density localized on that unit specifically, the saturated bridge preventing delocalization between the two moieties (Figure S11). Second the MO diagrams of hyd-ZnP-TEMPO (Figure S12) reveals that the unpaired electron of the TEMPO appears slightly below the HOMO located on the ZnP unit. The computed difference is $-0.21 \mathrm{eV}$, hinting at a small driving force for the hole shift, one hyd- 
ZnP-TEMPO is oxidized, which is consistent with the experimental findings. To have a more accurate evaluation of this energy difference (than with MOs), we have determined the adiabatic ionization potentials (including zero-point corrections) for the separated $\mathbf{Z n P}$ and TEMPO moieties by the $\triangle \mathrm{SCF}$ approach. The computed IP are 5.08 and $5.21 \mathrm{eV}$ for $\mathbf{Z n P}$ and TEMPO, respectively, leading to a driving force of $-0.13 \mathrm{eV}$ well in line with the electrochemical measurements.

\section{Photophysical study}

Electronic transient absorption (TA) measurements were performed with both hyd-ZnPTEMPO and the reference hyd-ZnP dye onto $\mathrm{TiO}_{2}$ films in the borate electrolyte. A first series of fs-ps measurements were carried out upon $550 \mathrm{~nm}$ excitation of films with an absorbance of about 0.4 at that wavelength (Figure 2A). Owing to the very high absorbance of the film in the Soret band region, no TA could be measured between 450 and $400 \mathrm{~nm}$. Directly after excitation, the TA spectra exhibit an intense excited-state absorption (ESA) band around $460 \mathrm{~nm}$ that can be attributed to the local $\mathrm{S}_{1}$ state of ZnP. ESA is also observed above $590 \mathrm{~nm}$ and is modulated by the overlapping negative contributions from the groundstate bleach (GSB) at $600 \mathrm{~nm}$ as well as the stimulated emission (SE) around 610 and $660 \mathrm{~nm}$. The $460 \mathrm{~nm}$ band loses about $80 \%$ of its intensity within $100 \mathrm{ps}$ and the contribution of the SE at $670 \mathrm{~nm}$ decays as well. Subsequently, the $620-750 \mathrm{~nm}$ region is dominated by a broad ESA. Unambiguous assignment this ESA is difficult, because the radical cation, anion and the $\mathrm{T}_{1}$ state of $\mathrm{ZnP}$ are known to absorb in this region. ${ }^{67,}{ }^{68}$ However, the changes in the TA spectra are consistent with the formation of the radical cation of the $\mathrm{ZnP}$ subunit upon charge injection into $\mathrm{TiO}_{2}$. Unambiguous detection of $\mathrm{ZnP}$ cation was achieved with a second series of fs-ps TA measurements with low concentration of adsorbed dyes (absorbance of $\sim 0.05$ at $550 \mathrm{~nm}$ ) to allow for monitoring the Soret band region. Figure 2B shows that the decay of the $\mathrm{S}_{1}$ band at $460 \mathrm{~nm}$ is accompanied by a partial recovery of the GSB in the Soret region as well as by the rise of a new band at $405-410 \mathrm{~nm}$. The latter can be unambiguously assigned to the radical cation of $\mathrm{ZnP}{ }^{69,} 70$ This feature is usually difficult to detect because of its close proximity to the intense Soret band. The time evolution of the intensity of the $\mathrm{ZnP}$ cation band is depicted in the inset of Figure $2 \mathrm{~B}$. The rise of the cation band can be well reproduced using the sum of two exponential functions with 6.3 and 75 ps time constants and similar amplitudes. 

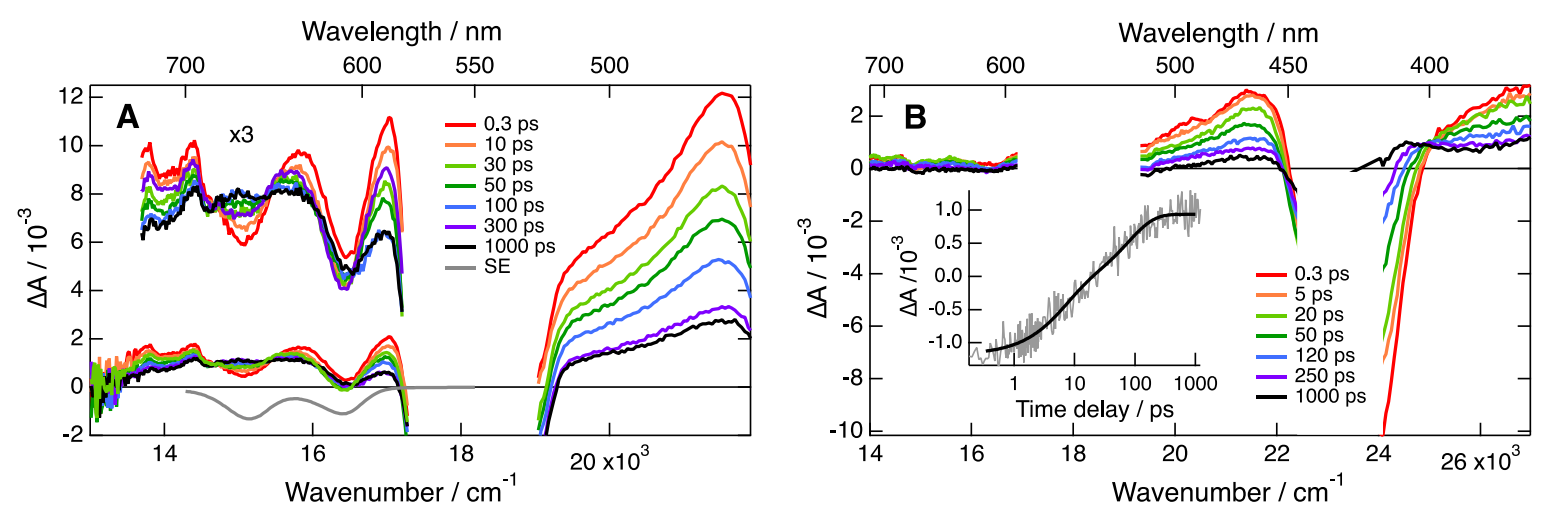

Figure 2. fs-ps transient absorption spectra recorded at various time delays after $550 \mathrm{~nm}$ excitation of $\mathrm{TiO}_{2}$ films with high (A) and low (B) concentrations of adsorbed hyd-ZnPTEMPO. The gray line in A represents the stimulated emission spectrum in acetonitrile. The inset in B shows the time evolution of the absorbance of the porphyrin cation band at $405 \mathrm{~nm}$.

The slower cation dynamics were monitored using ns- $\mu$ s TA upon $532 \mathrm{~nm}$ excitation. As shown in Figure 3, both the GSB and the ZnP cation bands decay concurrently on multiple timescales with 2, $50 \mathrm{~ns}$ and $10 \mu \mathrm{s}$ time constants to a weak residual spectrum with $>100 \mu \mathrm{s}$ decay time. Because of the absence of spectroscopic signature of the TEMPO cation in the $370-1500 \mathrm{~nm}$ region, it is impossible to determine whether the decay of the $\mathrm{ZnP}$ cation and the recovery of the GSB are due to a hole shift from $\mathrm{ZnP}$ cation to TEMPO or to charge recombination with the semi-conductor. The same TA measurements, performed with the hyd- $\mathbf{Z n P}$ reference compound in $\mathrm{TiO}_{2}$, also evidence the formation of the $\mathrm{ZnP}$ cation (Figure S13). The decay of the ZnP cation band does not differ significantly from that measured with hyd-ZnP-TEMPO (Figure S14). However, this similarity does not exclude occurrence of hole shift to TEMPO, but could result from a slow hole shift that only partially competes with recombination. This would be consistent with the weak driving force of this process $(\sim 0.1$ $\mathrm{eV})$. By comparison, intermolecular hole shifts between TEMPO and oxidized organic dyes on $\mathrm{TiO}_{2}$ with a driving force of 0.18 and $0.25 \mathrm{eV}$ were reported to occur with 6 and $31 \mu \mathrm{s}$, time constants, respectively. ${ }^{47}$ To check the feasibility of hole shift from $\mathrm{ZnP}$ cation to TEMPO, the radical cation of zinc tetraphenylporphyrine (ZnTPP) was generated upon bimolecular electron transfer with $0.02 \mathrm{M}$ maleic anhydride as electron acceptor in acetonitrile. Figure S15A and S16 show the buildup on the hundred of nanoseconds timescale of the ZnTPP cation band in the 405-410 nm region. If 0.02 M TEMPO is additionally present in the solution, the ZnTPP cation band is totally suppressed (Figure 15B). This is a clear evidence that hole shift from $\mathrm{ZnP}$ cation to TEMPO is operative. 


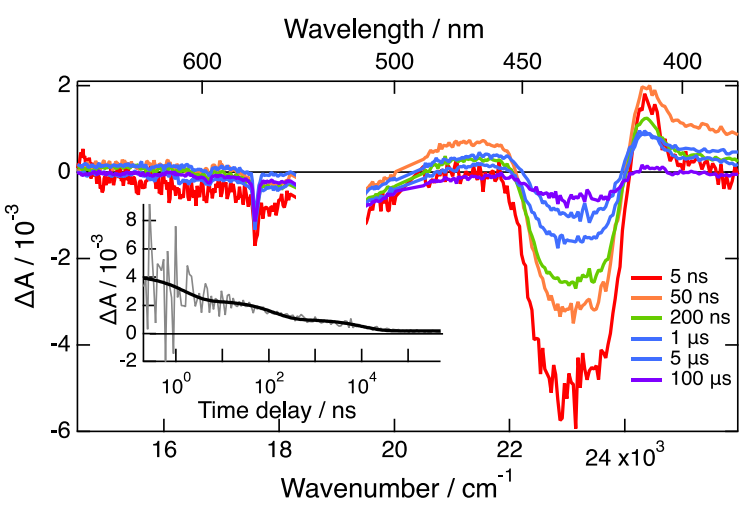

Figure 3. ns- $\mu$ s transient absorption spectra recorded at various time delays after $532 \mathrm{~nm}$ excitation of a $\mathrm{TiO}_{2}$ film with a low concentration of adsorbed hyd-ZnP-TEMPO. The inset shows the time evolution of the absorbance of the porphyrin cation band at $410 \mathrm{~nm}$.

\section{Photovoltaic performances in dye sensitized solar cells}

Although the primary goal of this study is not to develop new systems for photovoltaic cells, we were curious to assess the photovoltaic performances of these dyes in DSSC. First, it enables to screen the best dyeing conditions of the $\mathrm{TiO}_{2}$ films. Second, an effective "dyecatalyst" for DSPEC should produce photocurrent in DSSC, therefore the photovoltaic efficiency in DSSC can provide first insights into the potential of these systems for photocatalysis. First, different soaking times were investigated from 1 hours to 8 hours and it turns out that 3 hours is the optimal condition in the toluene/ethanol (1/1) at the concentration of $0.2 \mathrm{mM}$. Then, these conditions were used to chemisorb the dyes on nanocrytalline $\mathrm{TiO}_{2}$ electrodes that were used as photoanodes to fabricate DSSCs with iodide/triiodide redox couple in acetonitrile electrolyte (see experimental part for details). The metrics of the solar cells, such as short circuit current density (Jsc), open circuit voltage (Voc), fill factor (ff) and power conversion efficiency (PCE) are gathered in Table 2. Typical current/voltage curves and incident photon-to-current efficiency (IPCE) spectra are shown in Figure S17 and Figure S18 respectively.

Table 2. Metrics of the solar cells recorded with the different dye under calibrated AM1.5 (100 $\mathrm{mW} / \mathrm{cm}^{2}$ ) sunlight simulator.

\begin{tabular}{|c|c|c|c|c|}
\hline & $\begin{array}{c}\mathrm{J}_{\mathrm{SC}} \\
\left(\mathrm{mA} / \mathrm{cm}^{2}\right)\end{array}$ & $\begin{array}{c}\mathrm{V}_{\mathrm{OC}} \\
(\mathrm{mV})\end{array}$ & $\begin{array}{c}\text { FF } \\
(\%)\end{array}$ & $\begin{array}{c}\text { PCE } \\
(\%)\end{array}$ \\
\hline hyd-ZnP & $1.82 \pm 0.08$ & $573 \pm 3$ & $69 \pm 1$ & $0.72 \pm 0.01$ \\
\hline hyd-ZnP-TEMPO & $3.45 \pm 0.2$ & $632 \pm 5$ & $72 \pm 1$ & $1.65 \pm 0.05$ \\
\hline
\end{tabular}




\begin{tabular}{|c|c|c|c|c|}
\hline $\mathrm{HO}_{2} \mathrm{C}-\mathrm{ZnP}$ & $1.77 \pm 0.2$ & $570 \pm 2$ & $69 \pm 2$ & $0.70 \pm 0.02$ \\
\hline $\mathrm{HO}_{2} \mathrm{C}-\mathrm{ZnP}$-TEMPO & $4.3 \pm 0.4$ & $645 \pm 10$ & $72 \pm 2$ & $2.00 \pm 0.2$ \\
\hline
\end{tabular}

First, the PCEs of these porphyrin systems are indeed much lower than those of the champion push-pull porphyrin sensitizers, which reach PCEs around 13-14\%. ${ }^{71}{ }^{72}$ Compared with previously reported similar simple tetraryl zinc porphyrins, ${ }^{73}$ the dyes of this study display lower PCEs essentially due to their lower Jsc, although one publication from Diau and coworkers $^{74}$ reports similar performances as ours. It is likely that the electron withdrawing substituent (amide or ester) in trans position to the anchoring moiety modifies the electron distribution in the excited state that disfavors electron injection efficiency. Second, based on the results of the PV measurements, two important conclusions can be drawn. First, the "ZnPTEMPO" dyads outperform the parent reference zinc porphyrins lacking the TEMPO unit. This is the direct consequence of much higher Jsc and Voc when the TEMPO moiety is present, resulting in more than twice higher PCEs. The higher photovoltaic performances in DSSCs of the dyads can be logically ascribed to a longer-lived charge separated state resulting from the hole shift from the zinc porphyrin radical cation formed after electron injection in $\mathrm{TiO}_{2}$. Indeed, the longer distance between the $\mathrm{TiO}_{2}$ surface and the positive charge on TEMPO most certainly decreases the rate of charge recombination, which enhances the Voc and the Jsc. ${ }^{75}$ Although the driving force of the hole shift reaction is weak (about -0.1 $\mathrm{eV}$ ), it appears sufficient for it to occur quite efficiently. ${ }^{22 a}$ Second, the dyad with carboxylic acid anchoring group gives a little more photocurrent density than that with hydroxamic acid. Similar results were reported before and can be ascribed to faster electron injection in $\mathrm{TiO}_{2}$, probably due to a larger electronic coupling. ${ }^{58,60}$

\section{Photocatalytic performances in DSPEC}

The photocatalytic performances of the "ZnP-TEMPO" dyads were determined using MeO$\mathrm{Ph}-\mathrm{CH}_{2} \mathrm{OH}$, as it is a classical reference substrate used in many studies with TEMPO catalysts, although that the latter can be most certainly compatible with other alcohols (see below). ${ }^{36}$ In addition, two different media were explored, first an aqueous electrolyte, since water is the greenest solvent and second acetonitrile, because this organic solvent is potentially relevant for alcohols that are not water soluble. Moreover, acetonitrile is also compatible with $\mathrm{CO}_{2}$ to envision reduction photocatalysis, ${ }^{76}$ which might be a valuable reaction to perform at the cathode in future tandem photocatalytic devices. The photocatalytic properties were analyzed with the dye chemisorbed on nanocrystalline $\mathrm{TiO}_{2}$ films, similar as those used in DSSCs, but dipped in a electrolyte containing $50 \mathrm{mM}$ of $\mathrm{MeO}-\mathrm{Ph}-\mathrm{CH}_{2} \mathrm{OH}$ using a standard three-electrode PEC under 1 sun illumination (about $100 \mathrm{~mW} / \mathrm{cm}^{2}$ with $400 \mathrm{~nm}$ cutoff filter), with a platinum grid as the counter electrode and a saturated calomel electrode (SCE) as reference. The quantity of $\mathrm{MeO}-\mathrm{Ph}-\mathrm{CH}_{2} \mathrm{OH}$ produced in the electrolyte was determined by gas chromatography after light irradiation. 


\section{Measurements in aqueous electrolytes}

First, chopped light linear sweep voltammetry (LSV) of hyd-ZnP-TEMPO and hyd-ZnP between $0.3 \mathrm{~V}$ until $-0.5 \mathrm{~V}$ vs. SCE in borate buffer at $\mathrm{pH}=8$ with $\mathrm{MeO}-\mathrm{Ph}_{-} \mathrm{CH}_{2} \mathrm{OH}$ was conducted (Figure 4A). The current density is much higher with the dyad than with the zinc porphyrin lacking the TEMPO, evidencing the key role of this organo-catalyst. The photocurrent density decreases as the electrode is bias to negative potentials, however, it remains relatively high until $-0.3 \mathrm{~V}$ vs. SCE, meaning that, under light irradiation, the photoanode can perform alcohol oxidation at much more negative potential than in the dark (Figure S10). In these latter conditions, $\mathrm{MeO}-\mathrm{Ph}-\mathrm{CH}_{2} \mathrm{OH}$ oxidation arose at an onset potential of $0.74 \mathrm{~V} v s$. SCE, indicating that light irradiation enables a significant gain of $c a .1 \mathrm{~V}$. However, compare to the thermodynamic oxidation potential of benzyl alcohol $(-0.51 \mathrm{~V}$ vs. $\mathrm{SCE}$ at $\mathrm{pH}=8),{ }^{77}$ the applied potential is still more positive by about $0.5 \mathrm{~V}$.
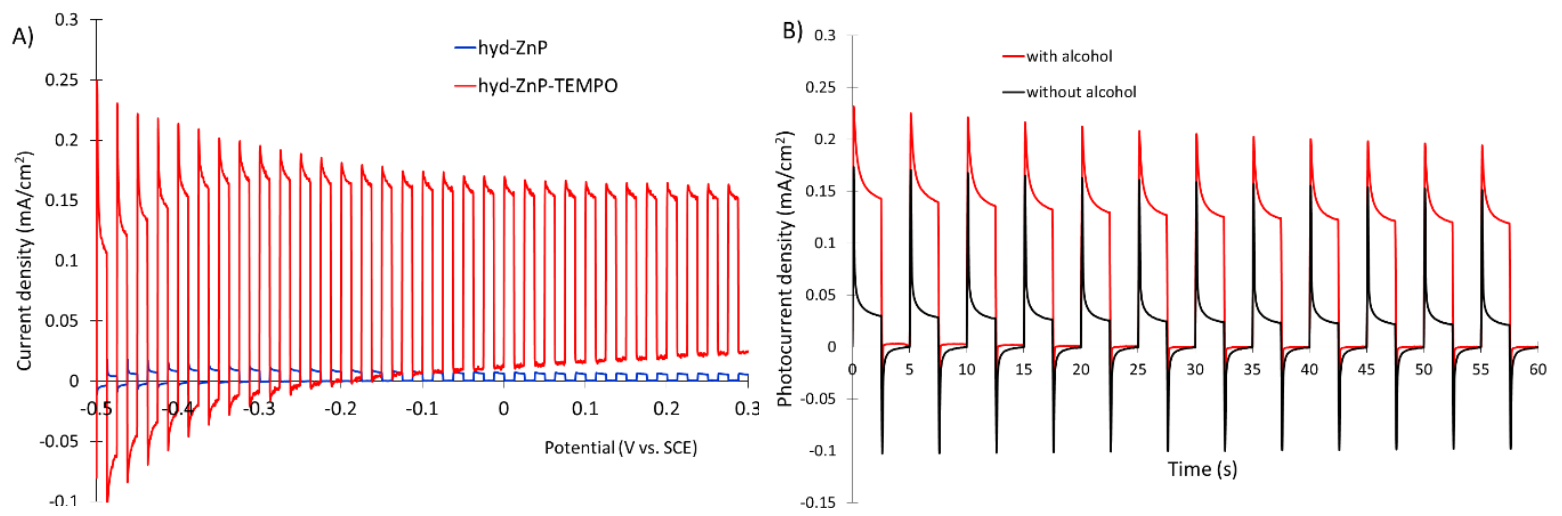

Figure 4. (A) chopped light linear sweep voltammetry measurements recorded under white light irradiation (white light Zhaner lamp about $350 \mathrm{~W} / \mathrm{m}^{2}$ ) of hyd-ZnP-TEMPO and hyd$\mathrm{ZnP}$ on $\mathrm{TiO}_{2}$ film with $0.1 \mathrm{M}$ borate buffer at $\mathrm{pH}=8$ containing $\left[\mathrm{MeO}-\mathrm{Ph}-\mathrm{CH}_{2} \mathrm{OH}\right]=50 \mathrm{mM}$, $\left[\mathrm{NaClO}_{4}\right]=0.1 \mathrm{M}$. Scan starts from $-0.5 \mathrm{~V}$ and ends at $0.3 \mathrm{~V} v s$. SCE with scan rate $5 \mathrm{mV} / \mathrm{s}$; (B) chopped light voltammetry measurements of hyd-ZnP-TEMPO recorded at a constant potential of $0 \mathrm{~V}$ vs. SCE with (red trace) and without (black trace) $\mathrm{MeO}-\mathrm{Ph}-\mathrm{CH}_{2} \mathrm{OH}(10 \mathrm{mM})$ in the same conditions as above.

Then, chopped light photocurrent densities were recorded at a constant potential of $0 \mathrm{~V} v s$. SCE for hyd-ZnP-TEMPO in borate buffer at $\mathrm{pH}=8$ in presence and in absence of alcohol (Figure 4B). In absence of $\mathrm{MeO}-\mathrm{Ph}-\mathrm{CH}_{2} \mathrm{OH}$, the photocurrent density is significantly lower than in presence of alcohol, indirectly testifying of the catalysis mediated by TEMPO. Moreover, without alcohol in solution the voltamogramm exhibits spikes of larger amplitudes during on and off light cycles. The cathodic spikes, observed when the light is turned off, probably result from charge recombination between the injected electrons in $\mathrm{TiO}_{2}$ and the oxidized TEMPO, because it cannot be reset to its neutral state by reaction with the alcohol. The spikes directly after light irradiation likely indicate that the photocurrent density is probably limited by mass transport of alcohol to the photocatalyst inside the pores of $\mathrm{TiO}_{2}$. 
Second the impact of the $\mathrm{pH}$ was examined, as it is reported that alcohol oxidation with TEMPO is $\mathrm{pH}$ dependent and usually works better in basic medium with an optimal $\mathrm{pH}$ situated around 10. ${ }^{36,62,63}$ Different electrolytes with borate buffer were used between $\mathrm{pH} 7.5$ and 10. The photocurrent responses under long term irradiation of hyd-ZnP-TEMPO at different pHs is shown in Figure S19 and the turnover number (TON), turnover frequency (TOF) and faradic efficiency (FE) are gathered in Table 3.

Table 3. Photocurrent densities, TONs, TOFs and FEs measured at different electrolytes with hydZnP-TEMPO or hyd-ZnP + ac-TEMPO on $1 \mathrm{~cm}^{2}$ nanocrystalline $\mathrm{TiO}_{2}$ films for $\mathrm{MeO}-\mathrm{Ph}-\mathrm{CH}_{2} \mathrm{OH}$ oxidation. Experiments with hyd-ZnP : [ac-TEMPO] $=1 \mathrm{mM}$.

\begin{tabular}{|c|c|c|c|c|c|c|}
\hline Catalyst & \multicolumn{5}{|c|}{ hyd-ZnP-TEMPO } & $\begin{array}{c}\text { hyd-ZnP + } \\
\text { ac-TEMPO }\end{array}$ \\
\hline Electrolyte & $\begin{array}{c}\text { Borate } \\
\mathrm{pH}=7.5\end{array}$ & $\begin{array}{c}\text { Borate } \\
\mathrm{pH}=8\end{array}$ & $\begin{array}{c}\text { Borate } \\
\mathrm{pH}=9\end{array}$ & $\begin{array}{c}\text { Borate } \\
\mathrm{pH}=10\end{array}$ & $\begin{array}{c}\mathrm{CH}_{3} \mathrm{CN}+ \\
\text { MeImd }\end{array}$ & $\begin{array}{c}\mathrm{CH}_{3} \mathrm{CN}+ \\
\text { MeImd }\end{array}$ \\
\hline $\begin{array}{c}\mathrm{J} \text { at } 500 \mathrm{sec} \\
\left(\mathrm{mA} / \mathrm{cm}^{2}\right)\end{array}$ & $0.15 \pm 0.02$ & $0.20 \pm 0.05$ & $0.13 \pm 0.02$ & $0.09 \pm 0.02$ & $0.10 \pm 0.02$ & $0.12 \pm 0.04$ \\
\hline TON & $16 \pm 2$ & $26 \pm 4$ & $15 \pm 3$ & $9 \pm 2$ & $13 \pm 2$ & $10 \pm 2^{\mathrm{b}}$ \\
\hline $\begin{array}{c}\mathrm{TOF} \\
\left(\mathrm{h}^{-1}\right)\end{array}$ & $28 \pm 3$ & $47 \pm 7$ & $28 \pm 5$ & $15 \pm 4$ & $24 \pm 4$ & $\begin{array}{c}18 \pm 3^{\mathrm{b}} \\
(\%)\end{array}$ \\
\hline $\begin{array}{c}\mathrm{FE} \\
(\%)\end{array}$ & $86 \pm 5$ & $82 \pm 6$ & $80 \pm 10$ & $93 \pm 10$ & $76 \pm 8$ & $85 \pm 6$ \\
\hline
\end{tabular}

acalculated from the quantity of hyd-ZnP-TEMPO loaded on the electrode; ${ }^{\mathrm{b}}$ calculated from the quantity of hyd-ZnP loaded on the electrode and in parentheses from the number of mole of acTEMPO in solution.

The photocatalytic measurements, recorded under light irradiation at different pHs, provide several interesting information. First, the parent hyd-ZnP compound has no photocatalytic activity, since no significant quantity of para-methoxybenzaldehyde is found by gas chromatography analysis, even in the optimal conditions with borate buffer at $\mathrm{pH}=8$. Second in aqueous electrolytes, the dyad hyd-ZnP-TEMPO indeed catalyzes the photo-oxidation of $\mathrm{MeO}-\mathrm{Ph}-\mathrm{CH}_{2} \mathrm{OH}$ with a quite high efficiency since the $\mathrm{FE}$ is systemically superior or equal to 
$80 \%$ and the DSPEC can reach a sizeable current density of about $200 \mu \mathrm{A} / \mathrm{cm}^{2}$ at $\mathrm{pH}=8$. These values are relatively high in comparison with those previously reported for alcohol oxidation in DSPEC with ruthenium catalyst, ${ }^{19,28-30,33}$ but also those usually obtained for water oxidation in $\mathrm{TiO}_{2}$ based DSPECs ${ }^{19,}{ }^{31}$ or for $\mathrm{H}_{2}$ evolution in NiO DSPECs, ${ }^{78}$ in which much lower photocurrent densities are typically measured. As anticipated the photocatalytic efficiency is $\mathrm{pH}$ dependent, but the maximum rate and efficiency are reached at $\mathrm{pH}=8$ and decreases at higher $\mathrm{pH}$. Both the rate of photocatalysis, reflected by the current density, and the overall efficiency depend on the intrinsic catalytic activity of TEMPO, the mass transport within $\mathrm{TiO}_{2}$ pores and the stability of the photocatalyst, both in terms of compound degradation (dye or catalyst) and desorption from the $\mathrm{TiO}_{2}$ electrode. The observation that the photocurrent decreases more steeply with irradiation time when the $\mathrm{pH}$ exceeds 8 suggests higher desorption and degradation rate of the photocatalyts at high $\mathrm{pH}$ (Figure S19). However, the absorption spectra of the $\mathrm{TiO}_{2}$ photoelectrode recorded before and after 1 hour of photolysis at $\mathrm{pH}=8$ are quite similar; indicating that dye desorption is probably not the main cause of photocatalytic loss in these conditions at $\mathrm{pH}=8$ (Figure S20). The fact that the photocatalysis decreases for $\mathrm{pH}$ above 8 , while the electrocatalytic oxidation rate constant of TEMPO increases with $\mathrm{pH}$, could mean that the rate of photocatalysis is limited by the diffusion of the alcohol inside the voids of $\mathrm{TiO}_{2}$ or that the TEMPO degrades faster in more basic conditions. It was indeed reported that TEMPO is not stable at high $\mathrm{pH}^{79}$ In addition, the assumption that photocatalysis is controlled by mass transport is supported by the chopped light linear voltammetry measurements showing that the steady state photocurrent density is lower than that observed immediately after light irradiation (Figure 4). As generally observed in previously reported DSPEC, the photocurrent steadily decreases upon photocatalysis questioning the cause of this deleterious process (Figure S19). Towards this goal, we have investigated the effect of adding ac-TEMPO in the electrolyte to see whether the catalytic activity would be restored. After the run of one hour of photocatalysis in borate buffer, the photoelectrode was transferred in acetonitrile electrolyte and gives a significant photocurrent density (about $200 \mu \mathrm{A} / \mathrm{cm}^{2}$ ). Then, after 100 seconds of light irradiation a concentrated solution of ac-TEMPO was added into the electrolyte (to reach a final concentration $1 \mathrm{mM}$ in the electrolyte). Interestingly, the photocurrent density did not change, suggesting that the degradation of TEMPO unit in the dyad is probably not the main reason of performances degradation. As a result, we assume that the degradation of the zinc porphyrin during catalysis might be the limiting factor of the long-term stability of the present system. Employing more photo- and/or electro-chemically stable dyes would likely enhance the stability of this type of DSPEC.

Finally, the Incident Photon-to-electron Conversion Efficiency (IPCE) spectrum of the dyad hyd-ZnP-TEMPO was recorded in the optimal conditions of borate buffer at $\mathrm{pH}=8$ (Figure 5). The maximum value reaches ca. $2.6 \%$ on the Soret band at $430 \mathrm{~nm}$ and the IPCE spectrum matches well with the absorption bands of the zinc porphyrin of the dyad recorded in a thin $\mathrm{TiO}_{2}$ film. In summary, the dyad hyd-ZnP-TEMPO is an efficient photocatalyst on $\mathrm{TiO}_{2}$ for benzyl alcohol oxidation, since it produces a quite significant photocurrent density and exhibits notable TON and TOF in comparison with other values reported in DSPECs for alcohol oxidation (Table S1). 


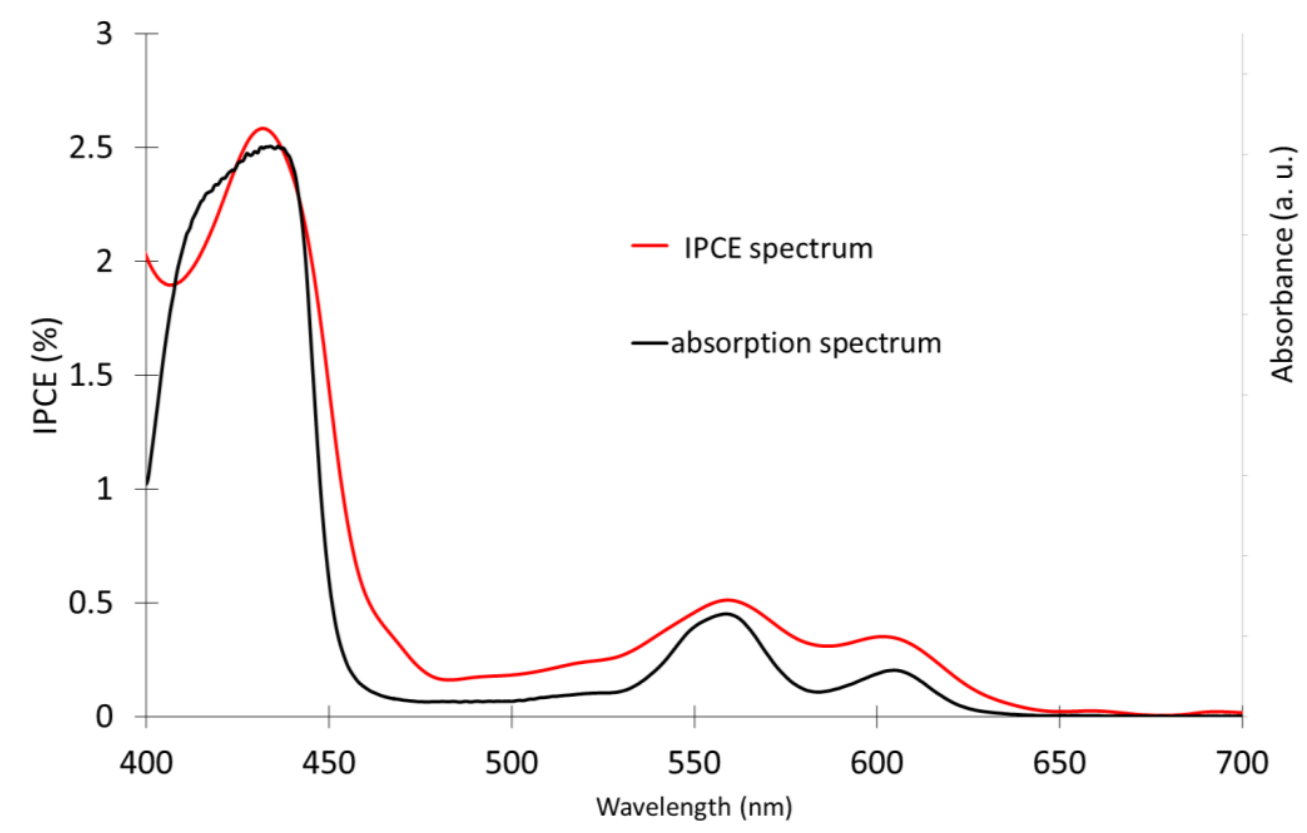

Figure 5. IPCE spectrum of hyd-ZnP-TEMPO recorded at a constant potential of $0 \mathrm{~V} v s$. SCE in borate buffer at $\mathrm{pH}=8$ and its and absorption spectrum recorded on thin $(4 \mu \mathrm{m})$ nanocristalline $\mathrm{TiO}_{2}$ film without scattering layer.

\section{Measurements in acetonitrile electrolyte}

Electro-oxidation of alcohol by TEMPO is abundantly described in organic solvents in the presence of a base, as the formation of aldehyde is accompanied by a proton release. In this study, acetonitrile was used as solvent, because it is compatible with proton reduction and even more interesting for $\mathrm{CO}_{2}$ reduction as $\mathrm{CO}_{2}$ is more (7-8 times) soluble in acetonitrile than in water. ${ }^{76}$ Two organic bases, 2,6-lutidine and N-methyl-imidazole (Me-Imd) usually used for this purpose, were investigated here. ${ }^{36}$ Chopped light photocurrent densities were recorded at a constant potential of $0 \mathrm{~V} v s$. SCE with $\mathrm{TiO}_{2}$ film coated with hyd-ZnP-TEMPO in presence of different concentrations of these two bases (Figure 6). The optimal concentrations of lutidine and $\mathrm{N}$-methyl-imidazole are $10 \mathrm{mM}$ and $100 \mathrm{mM}$ respectively and $\mathrm{N}$-methyl-imidazole gives much higher photocurrent densities than lutidine (about 3 folds). This is certainly due to the higher basicity of N-methyl-imidazole and the possibility to bind axially to $\mathrm{ZnP}$ which limits aggregation. 

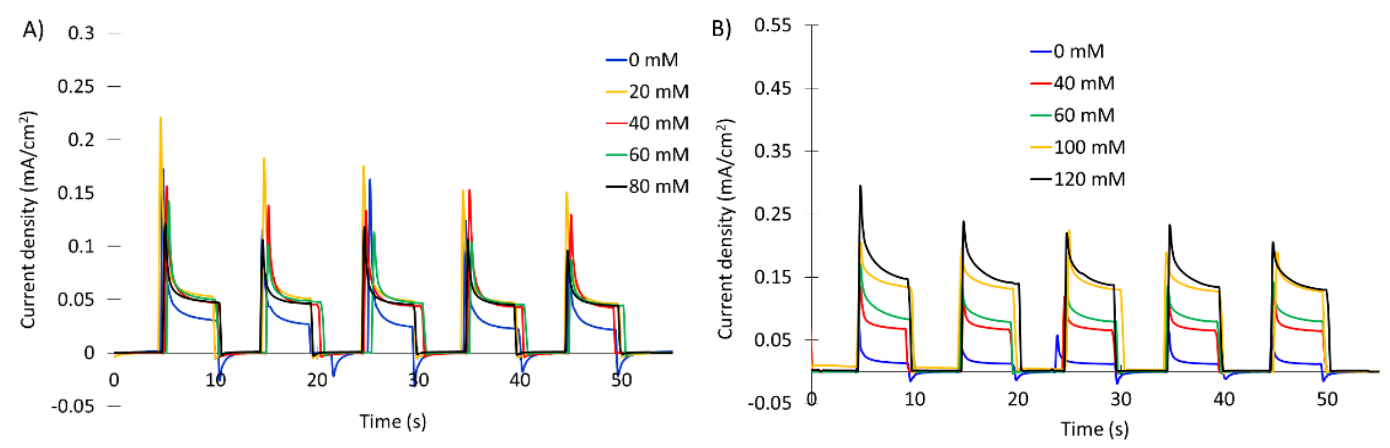

Figure 6. Chopped light voltammetry measurements of hyd-ZnP-TEMPO recorded at a constant potential of $0 \mathrm{~V} v s$. SCE in presence of different concentrations of (A) 2,6-lutidine and (B) N-methylimidazole in acetonitrile recorded under white light irradiation $\left(1000 \mathrm{~W} / \mathrm{m}^{2}\right)$ with $\mathrm{MeO}-\mathrm{Ph}-\mathrm{CH}_{2} \mathrm{OH}$ $(50 \mathrm{mM})$ and $\left[\mathrm{LiClO}_{4}\right]=0.1 \mathrm{M}$.

Long term photolysis experiments were then conducted with Me-Imd at $100 \mathrm{mM}$ in acetonitrile to determine the photocatalytic efficiency of hyd-ZnP-TEMPO in these conditions (Table 3 and Figure S21). Compared to borate buffer at $\mathrm{pH}=8$, the efficiency is significantly lower, as the values of TON and TOF are reduced by about a factor of two. This is certainly the consequence of a faster desorption rate of the photocatalyst in acetonitrile, because the dyad is much more soluble in acetonitrile than in the borate buffer (see below).

\section{Measurements with other benzyl alcohol substrates}

Although the chosen catalyst ac-TEMPO is known to be a very active system for many alcohol substrates, ${ }^{36,62,80}$ two other benzyl alcohols: namely benzyl alcohol $\left(\mathrm{Ph}^{\left.-\mathrm{CH}_{2} \mathrm{OH}\right)}\right.$ and para trifluoromethyl benzyl alcohol $\left(\mathrm{CF}_{3}-\mathrm{Ph}-\mathrm{CH}_{2} \mathrm{OH}\right)$ an electron deficient substrate were studied both in borate buffer at $\mathrm{pH} 8$ and in acetonitrile electrolyte in presence of methyl imidazole. The average photocurrent densities measured after $500 \mathrm{sec}$ of photocatalysis are gathered in Table 4 and the current versus time curves are shown in Figure S22.

Table 4. Photocurrent densities recorded at $500 \mathrm{sec}$ during the photocatalysis experiments with hydZnP-TEMPO using three different benzyl alcohol substrates $(50 \mathrm{mM})$.

\begin{tabular}{|c|c|c|c|}
\hline & $\mathrm{MeO}-\mathrm{Ph}-\mathrm{CH}_{2} \mathrm{OH}$ & $\mathrm{Ph}-\mathrm{CH}_{2} \mathrm{OH}$ & $\mathrm{CF}_{3}-\mathrm{Ph}-\mathrm{CH}_{2} \mathrm{OH}$ \\
\hline Borate buffer $\mathrm{pH}=8$ & $0.20 \pm 0.05 \mathrm{~mA} / \mathrm{cm}^{2}$ & $0.19 \pm 0.08 \mathrm{~mA} / \mathrm{cm}^{2}$ & $0.50 \pm 0.05 \mathrm{~mA} / \mathrm{cm}^{2}$ \\
\hline $\mathrm{CH}_{3} \mathrm{CN}+\mathrm{Me}-\mathrm{Imd}$ & $0.10 \pm 0.02 \mathrm{~mA} / \mathrm{cm}^{2}$ & $0.10 \pm 0.01 \mathrm{~mA} / \mathrm{cm}^{2}$ & $0.11 \pm 0.02 \mathrm{~mA} / \mathrm{cm}^{2}$ \\
\hline
\end{tabular}

It was observed that in borate buffer, benzyl alcohol gives approximatively the same photocurrent density as $\mathrm{MeO}-\mathrm{Ph}-\mathrm{CH}_{2} \mathrm{OH}$, while $\mathrm{CF}_{3}-\mathrm{Ph}-\mathrm{CH}_{2} \mathrm{OH}$ produces much higher photocurrent density. We interpret this surprising result as the consequence of the higher hydrophobicity of $\mathrm{CF}_{3}-\mathrm{Ph}-\mathrm{CH}_{2} \mathrm{OH}$, which probably improves its affinity to the lipophilic environment of the $\mathrm{TiO}_{2}$ photoanode coated with organic moieties (porphyrin and TEMPO). This is supported by the measurements in acetonitrile, which give higher photocurrent 
densities in acetonitrile $v s$. borate buffer at the beginning of the experiments and similar photocurrent for all three substrates in acetonitrile electrolyte. Overall, these extra measurements show that these ZnP-TEMPO are quite active towards benzyl alcohol substrates in general, in agreement with previous studies, ${ }^{36,62,80}$ and that the wettability of the photoelectrode network by the substrate is certainly an important parameter to consider to maximize its contact with the catalytic surface hence the efficiency of the photocatalytic device. This is in agreement with other studies dealing with DSSC using water based electrolytes $^{81}$ and DSPEC for water oxidation. ${ }^{54}$

\section{Impact of covalent linkage of TEMPO with ZnP on the photocatalysis}

In DSPECs, the catalyst is generally covalently tethered to the photosensitizer or co-grafted with the latter on the surface of the semiconductor. ${ }^{31,32}$ In some rare cases, it is solubilized in the electrolyte. ${ }^{35,82}$ The latter approach presents the advantage of being simpler in term of synthesis, but requires a larger quantity of the catalyst and is less practical for its recycling as the latter must be separated from the product in the electrolyte. However, we investigated the photocatalytic performance of hyd-ZnP in association with ac-TEMPO in the electrolyte. In borate buffer at $\mathrm{pH}=8$ with $50 \mathrm{mM}$ of $\mathrm{MeO}-\mathrm{Ph}-\mathrm{CH}_{2} \mathrm{OH}$, increasing concentrations of acTEMPO from 0 to $10 \mathrm{mM}$ do not change the photocurrent density delivered by the $\mathrm{TiO}_{2}$ film sensitized by hyd-ZnP. This is most certainly attributable to the low solubility of ac-TEMPO in water, which prevents reaching a sufficient concentration to quickly react with the oxidized porphyrin before charge recombination. Then, the same experiment was conducted in the acetonitrile electrolyte containing Me-Imd by adding increasing quantities of ac-TEMPO (from $0 \mathrm{mM}$ to $10 \mathrm{mM}$, Figure S23). Interestingly, the photocurrent density of the photoelectrode sensitized by hyd-ZnP increases upon addition of ac-TEMPO, but it reaches a plateaus at around $1 \mathrm{mM}$. Then, long term photolysis experiments were undertaken in these conditions to compare the performances with the system in which the catalyst is appended to the zinc porphyrin (hyd-ZnP-TEMPO). Within experimental errors, the performances of the two systems are quite alike (Table 3 and Figure S21). Only TOF is significantly higher with hyd-ZnP-TEMPO than hyd-ZnP + ac-TEMPO and this can be understood as the consequence of a faster hole shift to the catalyst due to the proximity brought by covalent linkage. However, the recovery of the catalytic system is much easier with the dyad (simple rinsing of the photoelectrode) and quantity of the used catalyst is much lower with the dyad (84 nmol versus $7000 \mathrm{nmol}$ ).

\section{Comparison of hyd-ZnP-TEMPO with $\mathrm{HO}_{2} \mathrm{C}-\mathrm{ZnP}-\mathrm{TEMPO}$}

Having the dyad $\mathbf{H O}_{2} \mathbf{C}-\mathbf{Z n P - T E M P O}$ at our disposition, we have naturally investigated its photocatalytic performance in the optimized conditions both in borate buffer at $\mathrm{pH} 8$ and in acetonitrile with Me-Imd. In borate buffer, the photocurrent density was $230 \mu \mathrm{A} / \mathrm{cm}^{2}$ after 
500 seconds of irradiation, TON, TOF, and FE were $24,44 \mathrm{~h}^{-1}$ and $89 \%$, respectively. These values are very close to that measured with the dyad hyd-ZnP-TEMPO, indicating that the anchoring group does not significantly affect the photocatalytic efficiency of the system in aqueous medium. This result is in line with the photovoltaic performances recorded in DSSCs which are quite similar with both dyads, let alone a higher Jsc with $\mathbf{H O}_{2} \mathbf{C}-Z \mathbf{Z n P}$-TEMPO. The low solubility of both dyads in water limits their desorption from the $\mathrm{TiO}_{2}$ electrode. However, a close inspection of the photocurrent evolution as a function of irradiation time of this dyad with that of hyd-ZnP-TEMPO reveals that it decays more abruptly, pointing to a lower stability of carboxylic acid anchor (Figure S24). In acetonitrile electrolyte with MeImd, thedesorption of the dyad $\mathbf{H O}_{2} \mathbf{C}-\mathbf{Z n P}$-TEMPO is so fast that it prevents to measure the quantity of the produced aldehyde. In conclusion, the replacement of carboxylic acid anchoring group by hydroxamic acid imparts a more robust binding to titania electrode. This enhanced stability has little impact in aqueous electrolyte where the dyad is poorly soluble, but is becomes crucial in acetonitrile electrolyte in which the solubility is sufficiently high, enabling quick desorption of the dyad within few minutes.

\section{Conclusions}

A novel photocatalytic system consisting of a zinc porphyrin connected to a TEMPO organocatalyst was prepared and thoroughly investigated for solar driven benzyl alcohol oxidation in a $\mathrm{TiO}_{2}$ based DSPEC. The dyad hyd-ZnP-TEMPO effectively catalyzes methoxybenzyl alcohol oxidation upon light irradiation of a $\mathrm{TiO}_{2}$ based photoanode coated with this photocatalyst. The optimal performance was observed in aqueous electrolyte at $\mathrm{pH}=8$, but the system also works with similar efficiency in acetonitrile in presence of N-methylimidazole. However, in acetonitrile electrolyte, the leaching of the photocatalyst from the $\mathrm{TiO}_{2}$ electrode is undoubtedly the major reason for the decrease of the catalytic performance. On the other hand, in aqueous conditions, the porphyrin degradation is certainly the main cause for the observed reduction of catalytic efficiency. In spite of its low driving force, the hole shift reaction from the zinc porphyrin radical cation occurs quite efficiently, as proved by the enhanced photovoltaic performances in DSSC of the dyad hyd-ZnP-TEMPO relative to the parent zinc porphyrin lacking the TEMPO unit. The comparison of the dyad hyd-ZnPTEMPO with the bi-component system "hyd-ZnP + ac-TEMPO", that was possible in acetonitrile, indicates that both approaches give similar performances, but the recovery of the catalyst is easier with the dyad and the quantity of the catalyst involved is much lower. It is observed in this study that hydroxamic acid is undoubtedly a more stable anchoring group than carboxylic acid, but photocatalyst desorption represents a major source of instability only when the system is soluble in the electrolyte. When the dye is very insoluble in the medium, for example here in aqueous borate buffer, the decrease of the catalytic activity can be attributed to dye leaching from the electrode surface. This is another strong argument to develop fully organic photocatalytic systems for DSPECs, since charged transition metal complexes are more prone to water solubility. 
The performance of the presented photocatalytic system stands among the highest ever reported for alcohol oxidation in DSPECs (Table S1) and compares very well with most of those reported for oxygen or hydrogen evolution with such photoelectrosynthetic systems. As a result, alcohol photo-oxidation, and particularly those extracted from biomass, represents an attractive reaction to pair with water or $\mathrm{CO}_{2}$ reduction so as to develop tandem photoelectrosynthetic cells producing valuable compounds at both electrodes. Overall, the present investigation provides several significant information for the development of advanced catalytic photoanodes for DSPECs. First, TEMPO organo-catalyst is not only a cheaper but also a more efficient and more robust catalyst for alcohol oxidation than polypyridine ruthenium complexes classically used for the same purpose in DSPECs. Second, the two electron oxidation of alcohol is an interesting alternative to the four electron oxidation of water to develop higher performing photocatalytic systems for artificial photosynthesis. Indeed, quite good photocurrent densities were measured in DSPEC with a regular tetra-aryl zinc porphyrin, which is, however, a modest $\mathrm{TiO}_{2}$ sensitizer (as demonstrated with the moderate short circuit photocurrent density recorded in DSSC) and with a weak driving force for hole shift with TEMPO. As a consequence, much higher performances and longer stability could certainly be obtained with the strategy reported here, but by employing a more efficient and more robust $\mathrm{TiO}_{2}$ sensitizer that also displays a higher oxidation potential than $\mathrm{ZnP}$ or a TEMPO derivative with a lower catalytic potential than ac-TEMPO. There are indeed many $\mathrm{TiO}_{2}$ sensitizers ${ }^{83,84}$ and several TEMPO catalysts ${ }^{85}$ that fulfill these requirements. This attractive strategy might help in designing new catalytic photoanodes for DSPEC that will be more efficient and will provide valuable products in a greener and more sustainable manner.

\section{Acknowledgements}

We thank Agence Nationale pour la Recherche (ANR) for financial support of this work with PECALO project (ANR-20-CE05-0019) and Conseil Régional des Pays de la Loire with LUMOMAT project. This research was funded by the General Secretariat for Research and Technology (GSRT) and Hellenic Foundation for Research and Innovation (HFRI; project code: 508). This research has been co-financed by the European Union and Greek national funds through the Regional Operational Program "Crete 2014-2020," project code OPS:5029187. Moreover, the European Commission's Seventh Framework Program (FP7/2007-2013) under grant agreement no. 229927 (FP7-REGPOT-2008-1, Project BIOSOLENUTI) and the Special Research Account of the University of Crete are gratefully acknowledged for the financial support. Financial support from the Swiss National Science Foundation (grant $\mathrm{nr}$ 200020- 184607) and the University of Geneva is also acknowledged. This work uses the computational resources of the CCIPL mesocenter installed in Nantes, to which DJ is strongly indebted.

The spectroscopic data can be downloaded from https://doi.org/10.26037/yareta:1s4a3qjbb5da3oxt4xpluskxcy 
Supporting Information available : experimental procedures for the synthesis of the compounds; supplementary transient absorption spectra; theoretical methods and diagrams of the frontier MOs; supplementary UV-vis absorption and emission spectra; cyclic voltammograms ; current/voltage characteristics of the DSSCs and their IPCE spectra ; photocurrent density responses during photolysis experiments; summary of the DSPECs performances for alcohol oxidation reported in the literature and ${ }^{1} \mathrm{H}$ and ${ }^{13} \mathrm{C}$ NMR spectra of the new compounds (PDF). This material is available free of charge via the Internet at http://pubs.acs.org.

\section{References}

1. Balzani, V.; Credi, A.; Venturi, M., Photochemical Conversion of Solar Energy. ChemSusChem 2008, $1,26-58$.

2. Dau, H.; Fujita, E.; Sun, L., Artificial Photosynthesis: Beyond Mimicking Nature. ChemSusChem 2017, 10, 4228-4235.

3. Barber, J.; Tran, P. D., From Natural to Artificial Photosynthesis. J. R. Soc. Interface 2013, 10, 20120984.

4. Kirner, J. T.; Finke, R. G., Water-oxidation Photoanodes using Organic Light-Harvesting Materials: a Review. J. Mater. Chem. A 2017, 5, 19560-19592.

5. Pinaud, B. A.; Benck, J. D.; Seitz, L. C.; Forman, A. J.; Chen, Z.; Deutsch, T. G.; James, B. D.; Baum, K. N.; Baum, G. N.; Ardo, S.; Wang, H.; Miller, E.; Jaramillo, T. F., Technical and Economic Feasibility of Centralized Facilities for Solar Hydrogen Production via Photocatalysis and Photoelectrochemistry. Energy Environ. Sci. 2013, 6, 1983-2002.

6. Yang, X.; Wang, D., Photocatalysis: From Fundamental Principles to Materials and Applications. ACS Appl. Energy Mater. 2018, 1, 6657-6693.

7. Liang, X.; Cao, X.; Sun, W.; Ding, Y., Recent Progress in Visible Light Driven Water Oxidation Using Semiconductors Coupled with Molecular Catalysts. ChemCatChem 2019, 11, 6190-6202.

8. Zhang, B.; Sun, L., Artificial Photosynthesis: Opportunities and Challenges of Molecular Catalysts. Chem. Soc. Rev. 2019, 48, 2216-2264.

9. Lhermitte, C. R.; Sivula, K., Alternative Oxidation Reactions for Solar-Driven Fuel Production. ACS Catal. 2019, 9, 2007-2017.

10. Kampouri, S.; Stylianou, K. C., Dual-Functional Photocatalysis for Simultaneous Hydrogen Production and Oxidation of Organic Substances. ACS Catal. 2019, 9, 4247-4270.

11. Xu, Y.; Zhang, B., Recent Advances in Electrochemical Hydrogen Production from Water Assisted by Alternative Oxidation Reactions. ChemElectroChem 2019, 6, 3214-3226.

12. Reid, Lacey M.; Li, T.; Cao, Y.; Berlinguette, C. P., Organic Chemistry at Anodes and Photoanodes. Sustainable Energy Fuels 2018, 2, 1905-1927.

13. Mei, B.; Mul, G.; Seger, B., Beyond Water Splitting: Efficiencies of Photo-Electrochemical Devices Producing Hydrogen and Valuable Oxidation Products. Adv. Sustainable Syst. 2017, 1, 1600035.

14. Cha, H. G.; Choi, K.-S., Combined Biomass Valorization and Hydrogen Production in a Photoelectrochemical Cell. Nature Chem. 2015, 7, 328.

15. Wang, F.; Stahl, S. S., Electrochemical Oxidation of Organic Molecules at Lower Overpotential: Accessing Broader Functional Group Compatibility with Electron-Proton Transfer Mediators. Acc. Chem. Res. 2020, 53, 561-574.

16. Organic Syntheses by Oxidation with Metal Compounds. Springer: Boston, MA, 1986.; p 908.

17. Granone, L. I.; Sieland, F.; Zheng, N.; Dillert, R.; Bahnemann, D. W., Photocatalytic Conversion of Biomass into Valuable Products: a Meaningful Approach? Green Chem. 2018, 20, 1169-1192. 
18. Bae, D.; Seger, B.; Vesborg, P. C. K.; Hansen, O.; Chorkendorff, I., Strategies for Stable Water Splitting via Protected Photoelectrodes. Chem. Soc. Rev. 2017, 46, 1933-1954.

19. Song, W.; Vannucci, A. K.; Farnum, B. H.; Lapides, A. M.; Brennaman, M. K.; Kalanyan, B.; Alibabaei, L.; Concepcion, J. J.; Losego, M. D.; Parsons, G. N.; Meyer, T. J., Visible Light Driven Benzyl Alcohol Dehydrogenation in a Dye-Sensitized Photoelectrosynthesis Cell. J. Am. Chem. Soc. 2014, 136, 9773-9779.

20. Xu, P.; McCool, N. S.; Mallouk, T. E., Water Splitting Dye-Sensitized Solar Cells. Nano Today 2017, 14, 42-58.

21. Bozal-Ginesta, C.; Mesa, C. A.; Eisenschmidt, A.; Francàs, L.; Shankar, R. B.; Antón-García, D.; Warnan, J.; Willkomm, J.; Reynal, A.; Reisner, E.; Durrant, J. R., Charge Accumulation Kinetics in Multi-Redox Molecular Catalysts Immobilised on $\mathrm{TiO}_{2}$. Chem. Sci. 2021, 12, 946-959.

22. Bold, S.; Massin, J.; Giannoudis, E.; Koepf, M.; Artero, V.; Dietzek, B.; Chavarot-Kerlidou, M., Spectroscopic Investigations Provide a Rationale for the Hydrogen-Evolving Activity of DyeSensitized Photocathodes Based on a Cobalt Tetraazamacrocyclic Catalyst. ACS Catal. 2021, 11, 3662-3678.

23. Ashford, D. L.; Song, W.; Concepcion, J. J.; Glasson, C. R. K.; Brennaman, M. K.; Norris, M. R.; Fang, Z.; Templeton, J. L.; Meyer, T. J., Photoinduced Electron Transfer in a Chromophore-Catalyst Assembly Anchored to $\mathrm{TiO}_{2}$. J. Am. Chem. Soc. 2012, 134, 19189-19198.

24. Shan, B.; Nayak, A.; Brennaman, M. K.; Liu, M.; Marquard, S. L.; Eberhart, M. S.; Meyer, T. J., Controlling Vertical and Lateral Electron Migration Using a Bifunctional Chromophore Assembly in Dye-Sensitized Photoelectrosynthesis Cells. J. Am. Chem. Soc. 2018, 140, 6493-6500.

25. Chen, H.-Y.; Ardo, S., Direct Observation of Sequential Oxidations of a Titania-Bound Molecular Proxy Catalyst Generated Through Illumination of Molecular Sensitizers. Nature Chem. 2018, 10, 17 23.

26. Hu, K.; Meyer, G. J., Lateral Intermolecular Self-Exchange Reactions for Hole and Energy Transport on Mesoporous Metal Oxide Thin Films. Langmuir 2015, 31, 11164-11178.

27. Moia, D.; Vaissier, V.; López-Duarte, I.; Torres, T.; Nazeeruddin, M. K.; O'Regan, B. C.; Nelson, J.; Barnes, P. R. F., The Reorganization Energy of Intermolecular Hole Hopping Between Dyes Anchored to Surfaces. Chem. Sci. 2014, 5, 281-290.

28. Treadway, J. A.; Moss, J. A.; Meyer, T. J., Visible Region Photooxidation on $\mathrm{TiO}_{2}$ with a Chromophore-Catalyst Molecular Assembly. Inorg. Chem. 1999, 38, 4386-4387.

29. Jiang, J.; Sherman, B. D.; Zhao, Y.; He, R.; Ghiviriga, I.; Alibabaei, L.; Meyer, T. J.; Leem, G.; Schanze, K. S., Polymer Chromophore-Catalyst Assembly for Solar Fuel Generation. ACS Appl. Mater. Interfaces 2017, 9, 19529-19534.

30. Badgurjar, D.; Shan, B.; Nayak, A.; Wu, L.; Chitta, R.; Meyer, T. J., Electron-Withdrawing Boron Dipyrromethene Dyes As Visible Light Absorber/Sensitizers on Semiconductor Oxide Surfaces. ACS Appl. Mater. Interfaces 2020, 12, 7768-7776.

31. Ashford, D. L.; Gish, M. K.; Vannucci, A. K.; Brennaman, M. K.; Templeton, J. L.; Papanikolas, J. M.; Meyer, T. J., Molecular Chromophore-Catalyst Assemblies for Solar Fuel Applications. Chem.Rev. 2015, 115, 13006-13049.

32. Brennaman, M. K.; Dillon, R. J.; Alibabaei, L.; Gish, M. K.; Dares, C. J.; Ashford, D. L.; House, R. L.; Meyer, G. J.; Papanikolas, J. M.; Meyer, T. J., Finding the Way to Solar Fuels with DyeSensitized Photoelectrosynthesis Cells. J. Am. Chem. Soc. 2016, 138, 13085-13102.

33. Pho, T. V.; Sheridan, M. V.; Morseth, Z. A.; Sherman, B. D.; Meyer, T. J.; Papanikolas, J. M.; Schanze, K. S.; Reynolds, J. R., Efficient Light-Driven Oxidation of Alcohols Using an Organic Chromophore-Catalyst Assembly Anchored to $\mathrm{TiO}_{2}$. ACS Appl. Mater. Interfaces 2016, 8, 9125-9133. 34. Charisiadis, A.; Glymenaki, E.; Planchat, A.; Margiola, S.; Lavergne-Bril, A.-C.; Nikoloudakis, E.; Nikolaou, V.; Charalambidis, G.; Coutsolelos, A. G.; Odobel, F., Photoelectrochemical Properties of Dyads Composed of Porphyrin/Ruthenium Catalyst Grafted on Metal Oxide Semiconductors. Dyes Pigments 2021, 185, 108908.

35. Li, S.; Li, Z.-J.; Yu, H.; Sytu, M. R.; Wang, Y.; Beeri, D.; Zheng, W.; Sherman, B. D.; Yoo, C. G.; Leem, G., Solar-Driven Lignin Oxidation via Hydrogen Atom Transfer with a Dye-Sensitized $\mathrm{TiO}_{2}$ Photoanode. ACS Energy Lett. 2020, 5, 777-784. 
36. Nutting, J. E.; Rafiee, M.; Stahl, S. S., Tetramethylpiperidine N-Oxyl (TEMPO), Phthalimide NOxyl (PINO), and Related N-Oxyl Species: Electrochemical Properties and Their Use in Electrocatalytic Reactions. Chem.Rev. 2018, 118, 4834-4885.

37. Ciriminna, R.; Pagliaro, M., Industrial Oxidations with Organocatalyst TEMPO and Its Derivatives. Org. Process Res. Dev. 2010, 14, 245-251.

38. Caron, S.; Dugger, R. W.; Ruggeri, S. G.; Ragan, J. A.; Ripin, D. H. B., Large-Scale Oxidations in the Pharmaceutical Industry. Chem. Rev. 2006, 106, 2943-2989.

39. Zhang, M.; Chen, C.; Ma, W.; Zhao, J., Visible-Light-Induced Aerobic Oxidation of Alcohols in a Coupled Photocatalytic System of Dye-Sensitized $\mathrm{TiO}_{2}$ and TEMPO. Angew. Chem. Int. Ed. 2008, 47, 9730-9733.

40. Nagasawa, T.; Allakhverdiev, S. I.; Kimura, Y.; Nagata, T., Photooxidation of Alcohols by a Porphyrin/Quinone/TEMPO System. Photochem. Photobiol. Sci. 2009, 8, 174-180.

41. Jeena, V.; Robinson, R. S., Convenient Photooxidation of Alcohols using Dye Sensitised Semiconductors in Combination with Silver Nitrate and TEMPO - an Electron Paramagnetic Resonance Study. Dalton Trans. 2012, 41, 3134-3137.

42. Jeena, V.; Robinson, R. S., Convenient Photooxidation of Alcohols using Dye Sensitised Zinc Oxide in Combination with Silver Nitrate and TEMPO. Chem. Commun. 2012, 48, 299-301.

43. Liu, D.; Zhou, H.; Gu, X.; ShNen, X.; Li, P., TEMPO-Mediated Oxidation of Primary Alcohols to Aldehydes under Visible Light and Air. Chin. J. Chem. 2014, 32, 117-122.

44. Li, T.; Kasahara, T.; He, J.; Dettelbach, K. E.; Sammis, G. M.; Berlinguette, C. P., Photoelectrochemical Oxidation of Organic Substrates in Organic Media. Nature Commun. 2017, 8, 390.

45. Bai, L.; Li, F.; Wang, Y.; Li, H.; Jiang, X.; Sun, L., Visible-Light-Driven Selective Oxidation of Benzyl Alcohol and Thioanisole by Molecular Ruthenium Catalyst Modified Hematite. Chem. Commun. 2016, 52, 9711-9714.

46. Chadderdon, D. J.; Wu, L.-P.; McGraw, Z. A.; Panthani, M.; Li, W., Heterostructured Bismuth Vanadate/Cobalt Phosphate Photoelectrodes Promote TEMPO-Mediated Oxidation of 5Hydroxymethylfurfural. ChemElectroChem 2019, 6, 3387-3392.

47. Yang, W.; Vlachopoulos, N.; Hao, Y.; Hagfeldt, A.; Boschloo, G., Efficient Dye Regeneration at Low Driving Force Achieved in Triphenylamine Dye LEG4 and TEMPO Redox Mediator Based DyeSensitized Solar Cells. Phys. Chem. Chem. Phys. 2015, 17, 15868-15875.

48. Zhang, Z.; Chen, P.; Murakami, T. N.; Zakeeruddin, S. M.; Grätzel, M., The 2,2,6,6-Tetramethyl1-piperidinyloxy Radical: An Efficient, Iodine- Free Redox Mediator for Dye-Sensitized Solar Cells. Adv. Funct. Mater. 2008, 18, 341-346.

49. Murakami, T.; Kato, F.; Oyaizu, K.; Nishide, H., Porphyrin-Dye Sensitized Solar Cell Utilizing Nitroxide Radical Mediator. J. Photopolymer Sci. Technology 2010, 23, 353-355.

50. Kato, F.; Kikuchi, A.; Okuyama, T.; Oyaizu, K.; Nishide, H., Nitroxide Radicals as Highly Reactive Redox Mediators in Dye-Sensitized Solar Cells. Angew. Chem. Int. Ed. 2012, 51, 1017710180.

51. Ishizuka, T.; Kotani, H.; Kojima, T., Characteristics and Reactivity of Ruthenium-oxo Complexes. Dalton Trans. 2016, 45, 16727-16750.

52. Nayak, A.; Hu, K.; Roy, S.; Brennaman, M. K.; Shan, B.; Meyer, G. J.; Meyer, T. J., Synthesis and Photophysical Properties of a Covalently Linked Porphyrin Chromophore-Ru(II) Water Oxidation Catalyst Assembly on $\mathrm{SnO}_{2}$ Electrodes. J. Phys. Chem. C 2018, 122, 13455-13461.

53. Wang, D.; Eberhart, M. S.; Sheridan, M. V.; Sherman, B. D.; Nayak, A.; Wang, Y.; Marquard, S. L.; Meyer, T. J.; Hu, K.; Dares, C. J., Stabilized Photoanodes for Water Oxidation by Integration of Organic Dyes, Water Oxidation Catalysts, and Electron-Transfer Mediators. Proc Natl Acad Sci U S A 2018, $115,8523-8528$.

54. Yamamoto, M.; Wang, L.; Li, F.; Fukushima, T.; Tanaka, K.; Sun, L.; Imahori, H., Visible LightDriven Water Oxidation using a Covalently-Linked Molecular Catalyst-Sensitizer Dyad Assembled on a $\mathrm{TiO}_{2}$ Electrode. Chem. Sci. 2016, 7, 1430-1439.

55. Moore, G. F.; Blakemore, J. D.; Milot, R. L.; Hull, J. F.; Song, H.-e.; Cai, L.; Schmuttenmaer, C. A.; Crabtree, R. H.; Brudvig, G. W., A Visible Light Water-Splitting Cell with a Photoanode Formed by Codeposition of a High-Potential Porphyrin and an Iridium Water-Oxidation Catalyst. Energy Environ. Sci. 2011, 4, 2389-2392. 
56. Orbelli Biroli, A.; Tessore, F.; Di Carlo, G.; Pizzotti, M.; Benazzi, E.; Gentile, F.; Berardi, S.; Bignozzi, C. A.; Argazzi, R.; Natali, M.; Sartorel, A.; Caramori, S., Fluorinated ZnII Porphyrins for Dye-Sensitized Aqueous Photoelectrosynthetic Cells. ACS Applied Mater. Interfaces 2019, 11, 3289532908.

57. Veldkamp, B. S.; Han, W.-S.; Dyar, S. M.; Eaton, S. W.; Ratner, M. A.; Wasielewski, M. R., Photoinitiated Multi-Step Charge Separation and Ultrafast Charge Transfer Induced Dissociation in a Pyridyl-Linked Photosensitizer-Cobaloxime Assembly. Energy Environ. Sci. 2013, 6, 1917-1928.

58. Koenigsmann, C.; Ripolles, T. S.; Brennan, B. J.; Negre, C. F. A.; Koepf, M.; Durrell, A. C.; Milot, R. L.; Torre, J. A.; Crabtree, R. H.; Batista, V. S.; Brudvig, G. W.; Bisquert, J.; Schmuttenmaer, C. A., Substitution of a Hydroxamic Acid Anchor into the MK-2 Dye for Enhanced Photovoltaic Performance and Water Stability in a DSSC. Phys. Chem. Chem. Phys. 2014, 16, 16629-16641.

59. McNamara, W. R.; Snoeberger Iii, R. C.; Li, G.; Richter, C.; Allen, L. J.; Milot, R. L.; Schmuttenmaer, C. A.; Crabtree, R. H.; Brudvig, G. W.; Batista, V. S., Hydroxamate Anchors for Water-Stable Attachment to $\mathrm{TiO}_{2}$ Nanoparticles. Energy Environ. Sci. 2009, 2, 1173-1175.

60. Higashino, T.; Kurumisawa, Y.; Cai, N.; Fujimori, Y.; Tsuji, Y.; Nimura, S.; Packwood, D. M.; Park, J.; Imahori, H., A Hydroxamic Acid Anchoring Group for Durable Dye-Sensitized Solar Cells Incorporating a Cobalt Redox Shuttle. ChemSusChem 2017, 10, 3347-3351.

61. Young, K. J.; Martini, L. A.; Milot, R. L.; Snoeberger, R. C.; Batista, V. S.; Schmuttenmaer, C. A.; Crabtree, R. H.; Brudvig, G. W., Light-Driven Water Oxidation for Solar Fuels. Coord. Chem. Rev. 2012, 256, 2503-2520.

62. Rafiee, M.; Miles, K. C.; Stahl, S. S., Electrocatalytic Alcohol Oxidation with TEMPO and Bicyclic Nitroxyl Derivatives: Driving Force Trumps Steric Effects. J. Am. Chem. Soc. 2015, 137, 14751-14757.

63. Hickey, D. P.; McCammant, M. S.; Giroud, F.; Sigman, M. S.; Minteer, S. D., Hybrid Enzymatic and Organic Electrocatalytic Cascade for the Complete Oxidation of Glycerol. J. Am. Chem. Soc. 2014, 136, 15917-15920.

64. Kim, D.; Lee, S.; Gao, G.; Seok Kang, H.; Ko, J., A Molecular-Clip-Based Approach to Cofacial Zinc-Porphyrin Complexes. J. Organomet. Chem. 2010, 695, 111-119.

65. Hagfeldt, A.; Graetzel, M., Light-Induced Redox Reactions in Nanocrystalline Systems. Chem.Rev. 1995, 95, 49-68.

66. Kavan, L.; Tétreault, N.; Moehl, T.; Grätzel, M., Electrochemical Characterization of $\mathrm{TiO}_{2}$ Blocking Layers for Dye-Sensitized Solar Cells. J. Phys. Chem. C 2014, 118, 16408-16418.

67. Rodriguez, J.; Kirmaier, C.; Holten, D., Optical Properties of Metalloporphyrin Excited States. J. Am. Chem. Soc. 1989, 111, 6500-6506.

68. Imahori, H.; Kang, S.; Hayashi, H.; Haruta, M.; Kurata, H.; Isoda, S.; Canton, S. E.; Infahsaeng, Y.; Kathiravan, A.; Pascher, T.; Chábera, P.; Yartsev, A. P.; Sundström, V., Photoinduced Charge Carrier Dynamics of $\mathrm{Zn}$-Porphyrin- $\mathrm{TiO}_{2}$ Electrodes: The Key Role of Charge Recombination for Solar Cell Performance. J. Phys. Chem. A 2011, 115, 3679-3690.

69. Okhrimenko, A. N.; Gusev, A. V.; Rodgers, M. A. J., Excited State Relaxation Dynamics of the Zinc(II) Tetraphenylporphine Cation Radical. J. Phys. Chem. A 2005, 109, 7653-7656.

70. Villamaina, D.; Bhosale, S. V.; Langford, S. J.; Vauthey, E., Excited-state Dynamics of Porphyrin-Naphthalenediimide-Porphyrin Triads. Phys. Chem. Chem. Phys. 2013, 15, 1177-1187.

71. Ji, J.-M.; Zhou, H.; Eom, Y. K.; Kim, C. H.; Kim, H. K., 14.2\% Efficiency Dye-Sensitized Solar Cells by Co-sensitizing Novel Thieno[3,2-b]indole-Based Organic Dyes with a Promising Porphyrin Sensitizer. Adv. Energy Mater. 2020, 10, 2000124.

72. Mathew, S.; Yella, A.; Gao, P.; Humphry-Baker, R.; Curchod, B. F. E.; Ashari-Astani, N.; Tavernelli, I.; Rothlisberger, U.; Nazeeruddin, M. K.; Grätzel, M., Dye-Sensitized Solar Cells with 13\% Efficiency Achieved Through the Molecular Engineering of Porphyrin Sensitizers. Nature Chem. 2014, 6, 242-247.

73. Kumar, R.; Sankar, M.; Sudhakar, V.; Krishnamoorthy, K., Synthesis and Characterization of Simple Cost-Effective Trans-A2BC Porphyrins with Various Donor Groups for Dye-Sensitized Solar Cells. New J. Chem. 2016, 40, 5704-5713.

74. Shrestha, M.; Si, L.; Chang, C.-W.; He, H.; Sykes, A.; Lin, C.-Y.; Diau, E. W.-G., Dual Functionality of BODIPY Chromophore in Porphyrin-Sensitized Nanocrystalline Solar Cells. J. Phys. Chem. C 2012, 116, 10451-10460. 
75. Bonhôte, P.; Moser, J.-E.; Humphry-Baker, R.; Vlachopoulos, N.; Zakeeruddin, S. M.; Walder, L.; Grätzel, M., Long-Lived Photoinduced Charge Separation and Redox-Type Photochromism on Mesoporous Oxide Films Sensitized by Molecular Dyads. J. Am. Chem. Soc. 1999, 121, 1324-1336.

76. Kumar, B.; Llorente, M.; Froehlich, J.; Dang, T.; Sathrum, A.; Kubiak, C. P., Photochemical and Photoelectrochemical Reduction of $\mathrm{CO}_{2}$. Annu. Rev. Phys. Chem. 2012, 63, 541-569.

77. Wang, Y.; Gonell, S.; Mathiyazhagan, U. R.; Liu, Y.; Wang, D.; Miller, A. J. M.; Meyer, T. J., Simultaneous Electrosynthesis of Syngas and an Aldehyde from $\mathrm{CO}_{2}$ and an Alcohol by Molecular Electrocatalysis. ACS Appl. Energy Mater. 2019, 2, 97-101.

78. Gibson, E. A., Dye-sensitized Photocathodes for $\mathrm{H}_{2}$ Evolution. Chem. Soc. Rev. 2017, 46, 61946209.

79. Golubev, V. A.; Sen', V. D., Mechanism of Autoreduction of 2,2,6,6-Tetramethyl-1,4Dioxopiperidinium Cation in Alkaline Medium. Russian J. Org. Chem. 2011, 47, 869-876.

80. Mercadante, M. A.; Kelly, C. B.; Bobbitt, J. M.; Tilley, L. J.; Leadbeater, N. E., Synthesis of 4Acetamido-2,2,6,6-Tetramethylpiperidine-1-Ooxoammonium Tetrafluoroborate and 4-Acetamido(2,2,6,6-Tetramethyl-Piperidin-1-yl)oxyl and their Use in Oxidative Reactions. Nature Protocols 2013, 8, 666-676.

81. Bella, F.; Gerbaldi, C.; Barolo, C.; Grätzel, M., Aqueous Dye-Sensitized Solar Cells. Chem. Soc.Rev. 2015, 44, 3431-3473.

82. Brimblecombe, R.; Koo, A.; Dismukes, G. C.; Swiegers, G. F.; Spiccia, L., Solar Driven Water Oxidation by a Bioinspired Manganese Molecular Catalyst. J. Am. Chem. Soc. 2010, 132, 2892-2894.

83. Ji, J.-M.; Zhou, H.; Kim, H. K., Rational Design Criteria for D- $\pi-A$ Structured Organic and Porphyrin Sensitizers for Highly Efficient Dye-Sensitized Solar Cells. J. Mater. Chem. A 2018, 6, 14518-14545.

84. Mishra, A.; Fischer, M. K. R.; Bäuerle, P., Metal-Free Organic Dyes for Dye-Sensitized Solar Cells: From Structure: Property Relationships to Design Rules. Angew. Chem. Int. Ed. 2009, 48, 24742499.

85. Zhang, K.; Noble, B. B.; Mater, A. C.; Monteiro, M. J.; Coote, M. L.; Jia, Z., Effect of heteroatom and Functionality Substitution on the Oxidation Potential of Cyclic Nitroxide Radicals: Role of Electrostatics in Electrochemistry. Phys. Chem. Chem. Phys. 2018, 20, 2606-2614. 


\section{Graphical abstract}
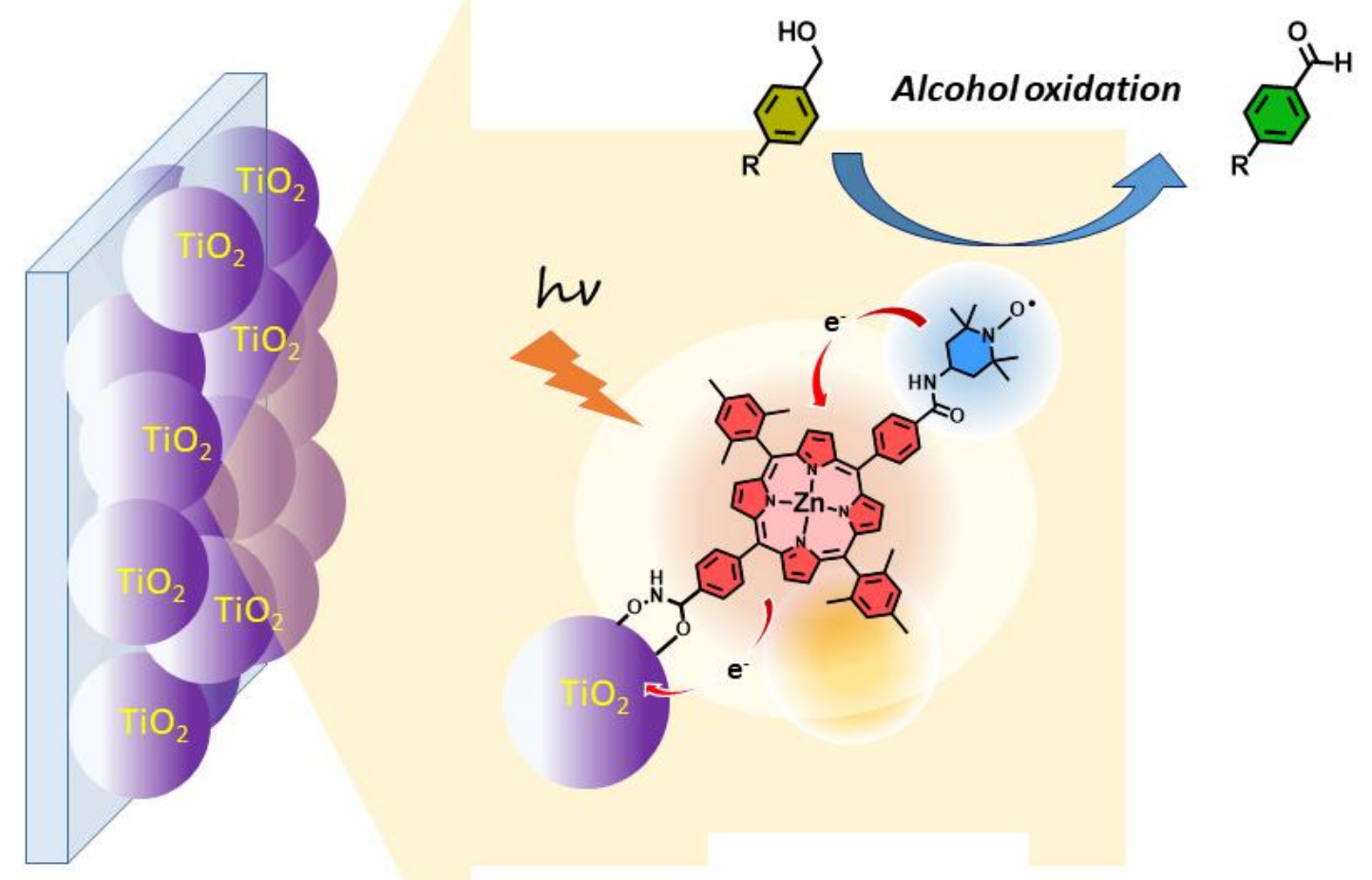